The research program of the Center for Economic Studies (CES) produces a wide range of theoretical and empirical economic analyses that serve to improve the statistical programs of the U.S. Bureau of the Census. Many of these analyses take the form of CES research papers. The papers are intended to make the results of CES research available to economists and other interested parties in order to encourage discussion and obtain suggestions for revision before publication. The papers are unofficial and have not undergone the review accorded official Census Bureau publications. The opinions and conclusions expressed in the papers are those of the authors and do not necessarily represent those of the U.S. Bureau of the Census. Republication in whole or part must be cleared with the authors.

\title{
REGIONAL INDUSTRIAL DOMINANCE, AGGLOMERATION ECONOMIES, AND MANUFACTURING PLANT PRODUCTIVITY
}

\author{
by \\ Joshua Drucker* \\ University of North Carolina at Chapel Hill
}

and

Edward Feser *

University of Illinois at Urbana-Champaign

CES 07-31 December, 2007

All papers are screened to ensure that they do not disclose confidential information. Persons who wish to obtain a copy of the paper, submit comments about the paper, or obtain general information about the series should contact sang V. Nguyen, Editor, Discussion Papers, Center for Economic Studies, Bureau of the Census, 4600 Silver Hill Road, 2K132F, Washington, DC 20233, (301-763-1882) or INTERNET address sang.v.nquyen@census.gov. 


\begin{abstract}
In a seminal article, Benjamin Chinitz (1961) focused attention on the effects that industry size, structure, and economic diversification have on firm performance and regional economies. He also raised a related but conceptually distinct question that has been overlooked since: how does the extent to which a regional industry is concentrated in a single or small number of firms impact the performance of other local firms within that industry? He suggested that such regional industrial dominance may impact input prices, limit capital accessibility, deter entrepreneurial activity, and reduce the regional availability of agglomeration economies such as specialized labor and supply pools In this paper, we use an establishment-level production function to quantify the links between industrial dominance, agglomeration economies, and firm performance. We consider two questions. First, do greater levels of regional industrial dominance lead to lower economic performance by small, dominated manufacturing plants? Second, are small plants in dominated regional industries more limited in capturing regional agglomeration benefits and therefore do they face rigidities in deploying production factors to maximum advantage? Our results suggest that regional industrial organization does influence productivity but that the effect tends to be a direct one, rather than an indirect effect via its influence on agglomeration economies.

* This work is supported by awards from the National Science Foundation (grant NSFBCS 0423900), the Ewing Marion Kauffman Foundation, and the North American Regional Science Council. Additional support for the Triangle Census Research Data Center comes from the National Science Foundation (grants NSF-SES 0004322 and NSF-ITR 0427889). Part of the research was conducted while the authors were Special Sworn Status researchers of the United States Census Bureau at the Triangle and Chicago Census Research Data Centers. The contents of this study have been screened to ensure that no confidential data are revealed. All contents and conclusions expressed are solely the responsibility of the authors and do not necessarily reflect the views of any of the supporting organizations or the United States Census Bureau.
\end{abstract}




\section{INTRODUCTION}

The relationship between industrial structure and economic performance has long interested researchers in regional science and industrial economics, as well as government officials and scholars and practitioners of economic development. Benjamin Chinitz' seminal article in the American Economic Review (1961) discussed the effects that industry size, structure, and economic diversification have on the regional availability and price of services and other specialized inputs, spurring considerable attention in the literature on these topics (e.g., Blair 1978; Acs and Audretsch 1990; Glaeser et al. 1992; Quigley 1998; Carree and Thurik 1999; Armington and Acs 2002). The article also identified a related but conceptually distinct issue that has been the subject of little empirical work: namely, whether regional industrial dominance-defined here as the extent to which a regional industry is concentrated in a single or small number of firms - affects the performance of other local firms within the same industry Chinitz suggested that regional concentration may act through input prices, capital accessibility, labor sharing or pooling, and the conduct of entrepreneurial activity to reduce the regional availability of agglomeration economies and ultimately diminish economic performance.

This paper poses and tests two hypotheses: first, that manufacturing plants located in regions where their industry is dominated by a few large firms achieve lower levels of performance than plants in the same industry that are situated in less dominated regions; and, second, that manufacturing establishments in dominated regional industries are less productive because they are less able to capture the benefits of agglomeration, reducing their capacity to deploy workforce, capital, and other factors of production to maximum advantage. We test the hypotheses using confidential micro-level data from the U.S. Census Bureau and productivity analysis conducted at the establishment level. Our approach resolves or avoids many of the theoretical and methodological pitfalls encountered in earlier studies of agglomeration economies. Ultimately, our results uphold the first hypothesis but falsify the second .

The paper proceeds as follows. In the next section, we review previous research relevant to the study of industrial organization and agglomeration. We then lay out a working theoretical framework, drawing heavily on Chinitz, followed by our empirical methodology, data sources, and variable definitions. We then provide a short descriptive picture of our study industries before reporting the results of our modeling effort. The final section summarizes and discusses policy implications. 


\section{PREVIOUS WORK}

Little theoretical or empirical work has been conducted directly on the specific issue of industrial dominance at the regional scale. One debate on the significance of Chinitz' paper focused on industrial diversity and average establishment size (e.g., Evans 1986; Carlino 1987; Norton 1992). Although study of these two regional characteristics has yielded useful information, the concepts are inadequate to test the two research hypotheses framing this study. Industrial diversity pertains to sectoral mix (the combination of economic activities in a region) rather than industrial structure, and both industrial diversity and average establishment size can provide only aggregate indications of the degree of industrial dominance in a region. Regional industrial dominance has separate implications for understanding the economic dynamics of the vast majority of regions that neither experience overriding economic dominance by a single firm or industry nor possess approximately competitive markets in each industry.

At the industry level, it is difficult to examine the implications of concentration because of the need to distinguish the effects of industrial structure from other influences on industryspecific performance (Gort and Sung 1999). Some empirical research suggests industrial concentration can affect performance negatively or positively, depending on the level of concentration (Caves and Barton 1990; Porter 1990; Nickell 1996; Nickell et al. 1997; Gopinath et al. 2004). Acs et al. (1999), for example, find that industries in which employment is more highly concentrated in large firms tend to have greater productivity growth, though they acknowledge that the effect could be due to survival bias. Empirical research on Gibrat's Law, the proposition that firm growth rates are independent of the firm size already attained, would seem to hold some promise for informing the question of regional dominance. However, Gibrat's Law was suggested initially to explain the skewed shape regularly found in the distribution of firm sizes (for reviews, see Sutton 1997; Caves 1998; Audretsch et al. 2004), and most of the research on the topic fails to consider location, tends to emphasize idiosyncratic or sector-specific factors behind observed industry differences (Schmalensee 1989; Davies and Geroski 1997), and is limited by a methodological approach — the matching of precisely defined distributions to empirical phenomena-that sets up hypotheses that cannot be evaluated with standard inferential statistics (Ijiri and Simon 1977; Powell 2003).

The theory of agglomeration offers the most suitable theoretical foundation for studying regional industrial dominance. Perhaps the earliest basis for postulating that the regional 
industrial context affects firm performance is Alfred Marshall's classic analysis of the benefits of firm co-location in specialized industrial districts ([1890] 1910). Considerable subsequent research has concentrated mainly on further clarifying the original three Marshallian types of agglomeration economies (access to suppliers, labor pools, and knowledge spillovers) and extending and measuring the list of possible agglomeration economy sources (Feser 1998; 2002). Many empirical studies of agglomeration economies use Hoover's (1937) distinction between localization and urbanization economies. There is serious doubt, however, as to whether urbanization and localization economies serve as adequate proxies for Marshall's agglomeration economy concepts in empirical work (Renski and Feser 2004). With respect to knowledge spillovers and innovation, Jacobs (1969) stresses the cross-fertilization of ideas across diverse industries, whereas Porter (1990) argues that competitive rivalry within industries is important. These "Jacobs externalities" and "Porter externalities" have often been tested against Marshall's concept of intra-industry knowledge spillovers (Audretsch 2003).

The most common empirical approach to investigating the influences of agglomeration economies is to examine productivity across a range of business environments, relating differences in measured or estimated productivity to indicators of local or regional agglomeration (Moomaw 1983; Fogarty and Garofalo 1988; Glaeser et al. 1992; Gerking 1994; Henderson et al. 1995; Malmberg 1996; Rosenthal and Strange 2004). ${ }^{1}$ Until the early 1990s or so, secondary data were rarely available at the firm level, so most agglomeration studies used city and industry size or density as a crude proxies for urbanization and localization economies or else concentrated specifically on knowledge spillovers. Recently, studies have developed more refined constructs in order to measure various sources of agglomeration externalities directly (Dumais et al. 1997; Feser 2001b; 2002; Rigby and Essletzbichler 2002; Koo 2005b; Renski 2006). The strategy permits a much closer analysis of the sources of agglomeration benefits, but also entails some practical shortcomings, chief among them the problems of obtaining suitable data and of variable multicolinearity that makes it difficult to distinguish among the effects of multiple sources of agglomeration economies (Renski and Feser 2004).

Much of the empirical research on agglomeration economies is encumbered by poor data and persistent methodological impediments. Despite these drawbacks, the preponderance of

\footnotetext{
${ }^{1}$ Alternate outcome measures such as employment growth, firm start-ups, the pace of innovation or technology adoption, or export intensity are variations on the same theme.
} 
evidence indicates that agglomeration substantially enhances economic performance, whether measured via productivity, employment growth, innovation, or firm formation (Gerking 1994; Feser 1998). It is not easy to draw broad conclusions beyond this general affirmation. The range of empirical results across industry sectors and geographic contexts underscores the importance of regional and industry-specific conditions in shaping the influence of agglomeration, and establishment-level analyses verify the significance of firm- and plant-level characteristics.

Two studies are important antecedents for this paper. In an establishment-level production function estimation aimed at modeling the influence of spatially attenuating sources of agglomeration economies, Feser (2002) investigated the influence of regional industrial organization on productivity by including a measure of manufacturing sector dominance as a key control. He found a strong positive relationship between a competitively organized manufacturing sector and productivity in a high technology industry (measuring and controlling devices), but a statistically insignificant relationship for a less technology-intensive industry (farm and garden equipment). He did not model the influence of industry-specific dominance or test for the intervening effect that dominance might have on firms' realization of agglomeration economies. Rosenthal and Strange (2003) utilized Dun \& Bradstreet's MarketPlace database to calculate indicators of corporate structure, regional-level industrial diversity, and concentric ring measures of localization and urbanization economies for six industries. They found that a higher concentration of regional industry employment in smaller establishments (which they describe as an "entrepreneurial industrial system") is associated with more firm births and newestablishment employment. Both studies report that agglomeration economies tend to attenuate with distance, but that various agglomeration effects differ markedly across industries.

Rosenthal and Strange conclude that "future studies of agglomeration economies should be sensitive both to industrial organization and especially to the micro geography of agglomeration" (2003, p. 388), both issues that we focus on here.

\section{A THEORETICAL FRAMEWORK}

A key hypothesis guiding this analysis posits that regional industrial dominance limits the ability of firms to deploy and adjust factors of production to maximum advantage. Following Chinitz, there are at least three pathways by which these limitations may occur: risk-taking, the availability of specialized inputs and services (including labor), and the availability of capital. 
Chinitz suggested that risk-taking behavior by smaller regional businesses may be reduced in the presence of large, profitable industry leaders that offer stable and lucrative employment to would-be entrepreneurs. In contrast, a competitive industrial environment encourages risk-taking, and thus entrepreneurial activity and the in-migration of entrepreneurs from other industries and regions. The relationship has been extended by subsequent authors. Individuals trained in large, stable enterprises are less likely to possess skill sets suited to establishing new businesses; a competitive industry environment is more conducive to developing general business savvy and honing skills relevant to entrepreneurial activities in related or supporting industries (Blair 1978; Booth 1986; Sorenson and Audia 2000). Large firms are more stable, and also generally offer greater compensation, benefits, and job security, reducing the incidence of career displacements that provide a common impetus for individual entrepreneurialism (Mason 1991; Wagner 2004; Hu et al. 2005). An environment of small, independent establishments is more supportive of entrepreneurial networks, group learning, and other entrepreneurial activities than a setting dominated by a small number of large firms (Porter 1990; Malecki 1994; Acs 1996; Carree and Thurik 1999; Enright 2000; Gordon and McCann 2000; Helmsing 2001). Regional social organizations and culture help to determine support for business risk-taking, and are shaped partly by the presence of or degree of corporate dominance within regional industries (Norton 1992; Rosenfeld 1996).

The propensity for risk-taking relates to innovation and the adoption of innovations within enterprises - the creation and diffusion of knowledge-as well as to the establishment of entrepreneurial ventures. Porter $(1990 ; 1998 ; 2000 ; 2002)$ argues that new business formation is essential for rivalry, which in turn is crucial for innovation and improvement as a survival criterion. ${ }^{2}$ Knowledge spillovers are thus more important in locally competitive than locally dominated environments (Scherer 1980; Malmberg and Maskell 2002), contradicting the earlier notion that innovation is favored in monopolistic settings where innovators capture more of the returns (Glaeser et al. 1992). Bureaucratic management structured to retain control over employees and maximize efficiency tends to inhibit innovation and spin-offs (Booth 1986; Saxenian 1994). Moreover, the establishment of specialized government- or industry-led institutes and associations, which help to generate and diffuse knowledge, is more probable with

\footnotetext{
${ }^{2}$ Porter discussed these ideas in a national context, but the concept extends to the regional scale where rivalry is spatially constrained.
} 
numerous rival firms that attract more public attention and have less capacity than larger firms to support research functions in-house (Scott 1988b; Porter 1998).

Regional corporate organization may also influence the incidence of localized externalities arising from access to specialized inputs. Not only does a region lacking industrial diversity support a narrow range of producer inputs and services, but large firms are usually more vertically integrated, curtailing accessible markets for specialized suppliers to serve other industry firms (Young 1928; Stigler 1951; Scott 1986; 1988a; Scott and Kwok 1989; Enright 1995; Porter 1998; Henderson et al. 2001). Inputs purchased externally by large firms are more likely to be from nonlocal suppliers (Mason 1991). Labor, particularly workers with specialized training, tends to gravitate toward large and stable employers (Audretsch 2001). Producers of specialized inputs and services favor the stability of large volume contracts and attend first to those purchasers with greater buying power (Nelson and Winter 1982; Booth 1986).

In contrast, an environment with many rivalrous firms mitigates the bargaining power of individual firms and expands supply, increasing competition and thus efficiency and performance within the supplier industry or labor market (Porter 1990; Helper 1991). To the extent that many potential buyers represent less risk to a supplier than one large buyer, there is more incentive for entry into supply industries. Firms supplying several industries may perceive less risk in adapting products and services for an industry with many rivals than for a largely isolated though sizeable enterprise. Public goods and specialized information are more likely to be available or tailored toward particular industry needs in regions in which an industry is competitively structured (Scott 1988b; Porter 1998; Mukkala 2004). Porter (1990) argues that potential job seekers are more likely to invest in obtaining industry-specific skills in the presence of rivalrous firms, and that the visibility of these firms helps stimulate the establishment of institutes and training centers that further support the development of specialized human capital.

Finally, finding adequate financing is crucial for minimizing business costs and enabling expansions, another possible link between dominance and firm production. Suitable and attractive financing is more likely to be accessible for competitively structured regional industries. Contrary to the predictions of neoclassical theory, capital availability varies across regions as well as among different industries and types of ventures (Clark et al. 1986; Mason 1991; Beck et al. 2005; Klagge and Martin 2005). Larger traditional regional lenders may prefer the greater collateral and perceived security of larger, established firms in market segments the 
lenders have come to understand (Cole et al. 2004; Usai and Vannini 2005). The costs of informing potential lenders of the soundness and potential profitability of investments are proportionately greater, often prohibitively so, for small firms (Berger and Udell 2002). Bankers and venture capitalists accustomed to entrepreneurial ventures are more accepting of and are better at assessing the risks of business formation and expansion. Thus industry financiers are more likely to adopt conservative lending patterns in regions and industries dominated by large stable employers (Booth 1986; Mason 1991; Norton 1992). External financing is typically more important for small firms (and absolutely essential for entrepreneurial ventures) with minimal capacity for internal financing (Clark et al. 1986; Berger and Udell 2002; Gilbert et al. 2006).

In the next section, we outline an approach to studying dominance and performance directly that uses production function methods applied at the establishment level. The methodology permits us to test the relationships between regional industry dominance, various types of commonly postulated sources of agglomeration economies, and firm performance within a single theoretical and empirical framework. Production theory, by relating inputs to outputs via the assumption of rational profit maximization, provides a natural link between regional factors such as industrial structure or dominance, agglomeration economies, and establishmentlevel performance, and grounds the analysis in a strong theoretical framework.

\section{EMPIRICAL FRAMEWORK}

A substantial body of empirical work investigates regional agglomeration economies through the use of production functions (see reviews in Moomaw 1983; 1988; Gerking 1994; Feser 1998; Rosenthal and Strange 2003). Research conducted in the 1980s and 1990s typically used publicly available regional or state-level data to estimate aggregate industry-level production functions for selected one- or two-digit Standard Industrial Classification (SIC) sectors. The approach suffers from two major problems: the ecological fallacy (i.e., aggregation bias) of inferring conclusions about plant or firm behavior from industry-level attributes, and the lack of industry-specific capital data at the regional scale. These defects led to wide variation and low reliability in the results.

The alternative of plant- or firm-level production function estimation has largely supplanted the earlier aggregate approach, despite the fact that the principal sources for the relevant micro-level data in the United States are confidential government-collected datasets to 
which relatively few researchers are able to obtain access. The appropriate application of microlevel data can overcome the methodological flaws of the aggregate production function approach: capital data is available for individual establishments, the assumption of profit maximization is reasonable at the firm level, and aggregation bias is not an issue. Moreover, production function parameters can be related to establishment-specific characteristics, and variables, such as those measuring agglomeration economies, can incorporate intraregional spatial variation. Many studies do not explicitly include agglomeration economies; those that do generally have found agglomeration economies to be substantial positive influences on productivity, albeit with mixed evidence on the relative importance of different types of agglomeration economies across industries and establishment sizes (Malmberg et al. 2000; Feser 2001a; 2001b; 2002; Rigby and Essletzbichler 2002; Henderson 2003).

This study estimates cross-sectional translog production functions to model the relationships between industry structure, agglomeration economies, and productivity. The translog form is both general and flexible, and strong assumptions such as homotheticity or constant returns to scale need not be imposed a priori. The tradeoff is that the large number of terms in the translog specification compels large samples and joint estimation with a set of derived cost share equations to achieve reasonable information efficiency (Kim 1992; Chung 1994; Feser 2002). Translog production functions have been successfully estimated in studies using Census micro-level data and incorporating non-standard input terms (Nguyen and Reznek 1990; Martin et al. 1991; Kim 1992; Feser 2001b; 2002; Moretti 2004).

The establishment-level production function is

$$
\begin{aligned}
\ln Q= & \alpha_{0}+\sum_{i} \alpha_{i} \ln X_{i}+\frac{1}{2} \sum_{i} \sum_{j} \beta_{i j}\left(\ln X_{i} \ln X_{j}\right) \\
& +\sum_{k} \gamma_{k} \ln Z_{k}+\sum_{i} \sum_{k} \mathrm{I}(i, k) \lambda_{i k} \ln X_{i} \ln Z_{k}+\sum_{k} \sum_{l} \mathrm{I}(k, l) \lambda_{k l} \ln Z_{k} \ln Z_{l}
\end{aligned}
$$

where $Q$ is establishment output; $X$ represents the four conventional inputs (capital, labor, energy, and materials); $Z$ is a vector of additional independent variables including regional industrial dominance, agglomeration economies, and relevant regional economic characteristics; $i$ and $j$ index the conventional inputs in $X$; and $k$ and $l$ index the other independent variables contained in $Z$. The indicator functions in the last two summands term allow for the selective inclusion of interaction terms. The first permits the independent variables in $Z$ to enter the production function in factor-augmenting form, i.e., altering the ratio of standard inputs used in 
production. The second set of interaction terms (implemented only with regional industrial dominance as the $Z_{k}$ term) allows incorporation of the square of dominance as an independent variable and estimation of the indirect effect that regional industrial dominance has on productivity through its influence on agglomeration advantages. The production function is estimated jointly with cost share equations for the conventional inputs derived from standard first-order conditions (Kim 1992; Feser 2002) (see Appendix A).

All non-dummy variables are mean centered to enter the production function. Those variables that are not already measured in percentage or ratio form are transformed with natural logarithms; the resulting coefficient estimates for the transformed variables are interpreted as elasticities at the sample means. Additive disturbance terms appended to the production function and cost share equations are assumed to follow a multivariate standard normal distribution. One cost share equation (energy) is dropped to avoid a singular covariance matrix. The model system is estimated using iterated nonlinear seemingly unrelated regression (Zellner efficient estimation) to allow for disturbances to be correlated across equations. The estimates are asymptotically equivalent to maximum likelihood estimates and are invariant to the choice of which cost share equation to omit (Berndt 1991; Greene 2003). The model is implemented using SAS's MODEL procedure. The specification assumes that the model variables are exogenous to the production function and cost share equations, an assertion that is inherently more reasonable at the level of individual establishments, particularly for small firms lacking market power, than in earlier regional-level studies.

We study three manufacturing industries: plastics and rubber (SIC 30), metalworking machinery (SIC 354), and measuring and controlling devices (SIC 382). These industries satisfy several criteria. They have enough establishments located in a sufficient number of regions to present adequate variation in the level of regional industrial dominance and a large enough overall sample size to support the translog estimation system. The industries have flexibility in location choice; none is closely tied to localized natural resources. They are relatively homogeneous in their production technologies. ${ }^{3}$ Lastly, the three industries present a contrast between traditional, established industries producing relatively stable, standardized products in a capital-intensive manner (rubber and plastics, metalworking machinery) and a more technology-

\footnotetext{
${ }^{3}$ According to data from the Benchmark Input-Output Accounts of the Bureau of Economic Analysis, the 4-digit SIC components of the study industries are relatively similar to each other in their nationwide purchasing relationships, compared to the components of other 2- and 3-digit SIC manufacturing sectors.
} 
and innovation-intensive industry (measuring and controlling devices). The results will provide a preliminary indication of whether the impacts of regional industrial dominance differ for traditional versus technology-based industries, given that the latter are typically subject to shorter innovation cycles.

The geographic regions used in this study are Labor Market Areas (LMAs) as defined by the Department of Agriculture using 1990 Census county-to-county commuting data (United States Department of Agriculture 2003). LMAs are appropriate since they cover the 48 states and approximate the boundaries of functional economic areas.

\section{DATA AND VARIABLE CONSTRUCTION}

Our primary data are confidential establishment-level records from the 1992, 1997, and 2002 Censuses of Manufactures as compiled in the Longitudinal Research Database (LRD) of the United States Census Bureau. (Additional data sources are detailed in Appendix B.) The LRD includes detailed information on inputs, outputs, locations (counties), and key establishment characteristics for nearly all manufacturing plants across the United States. The measures of conventional inputs, output, and cost shares are taken from the LRD (see Appendix B for construction details). Data from the LRD are combined with publicly available information to create establishment- and regional-level indicator and control variables.

Although the LRD includes information on all establishments in the United States reporting under a manufacturing SIC code, the smallest stand-alone plants (generally those with five or fewer employees) are exempt from filing requirements and all information in those records except employment, value of shipments, payroll, and name and address is imputed using industry average ratios. These "administrative records" are excluded from the samples; otherwise the analysis would in part reflect imputation rules rather than establishment-level productivity relationships (Feser 2001b; Henderson 2003). ${ }^{4}$ Establishments in Alaska and Hawaii are omitted from the samples due to their relatively isolated location; establishments in the three most populous LMAs are excluded as outliers because of those regions' unusual size, density, and volume of international linkages. ${ }^{5}$ Establishments with non-positive reported

\footnotetext{
${ }^{4}$ Administrative records are used in the measurement of regional industrial dominance; see below.

${ }^{5}$ The three most populous LMAs contain the city centers of New York, Los Angeles, and Chicago.
} 
employment, measures of output, capital, labor, energy, or materials, or cost shares are dropped from the samples as well.

Measuring Dominance. The operationalization of regional industrial dominance is key to this study, but as the concept has not appeared in quantitative empirical research, there is no strong theoretical or empirical basis upon which to base the selection of an appropriate measure. Previous work conducted at the industry scale has adopted indicators for industrial concentration or market power based on a variety of different measures, including concentration ratios, likelihood ratios, the Gini coefficient, the Herfindahl-Hirschman index, entropy measures, and the sample variance of firm size (Hay and Morris 1991; Amato 1995; Powell 2003; Powell and Lloyd 2005). Empirical comparisons conclude that no single measure is superior to the others. Concentration ratios may be the most widely used, in part because they are available from the Census at the national level in public-release versions of the Census of Manufactures (Golan et al. 1996). For this research, the concentration ratio carries the advantage that it is relatively insensitive to the pattern of firm sizes that occurs at the low end of the distribution, which accords with the theoretical conception of dominance described above. It is also appropriate given our necessary exclusion of the smallest plants from the estimation samples.

Regional industrial dominance is calculated as a five-firm concentration ratio: the percentage of total regional industry shipment value that is accounted for by the five largest ("dominator") firms. ${ }^{6}$ Establishments are aggregated to the level of firms based on the sameindustry same-region manufacturing components of multi-unit firms. The calculation of regional industrial dominance includes administrative records since the value of shipments is collected rather than imputed for all establishments, but the estimating samples omit the administrative records. Because regional industrial dominance is only a meaningful concept in situations in which "dominant" firms are distinguished from a larger set of non-dominant plants, observations in regions containing fewer than twelve firms in the industry are excluded from the samples.

Sources of Agglomeration Economies. The production model includes five measures of labor pooling, input and supply pooling, and knowledge spillovers, measured for each establishment. As in other studies, these variables estimate potential agglomeration economies based on observable characteristics (Richardson 1974). Unfortunately, there are no adequate

\footnotetext{
${ }^{6}$ Numerous versions of this dominance measure were tested, varying the parameters of the concentration ratio and substituting employment for shipment value. The outcomes are not discussed in this paper, but the conclusions described below are qualitatively robust with regard to the alternative specifications.
} 
data available both at the regional scale and on a nationwide basis that indicate capital or financing availability. In addition, data limitations and multicolinearity issues force compromises in the construction of the measures. ${ }^{7}$ The variables are conceptually similar to measures employed successfully in other recent agglomeration economies research (Feldman and Audretsch 1999; Drennan et al. 2002; Feser 2002; Rigby and Essletzbichler 2002; Renski and Feser 2004; Koo 2005b; Renski 2006). All of the variables except the labor pooling variable use absolute measurement scales. The five agglomeration indicators are based on establishment size rather than plant counts, since the external economies studied are dependent on the scale of productive activity rather than the division into economic units. Many of the flexible parameters were determined by empirically testing alternatives.

One advantage of using micro-level data is being able to include the spatial attenuation of agglomeration influences with increasing distance. The LRD contains establishment locations by county, allowing for enormous improvement over regionally-invariant agglomeration measures. Distance decay is commonly modeled with an exponential term, applying a weight factor of $d^{\alpha}$, where $d$ is distance and $\alpha$ is a parameter that can be varied, along with an absolute cutoff distance (Anselin 2002; Hu and Pooler 2002). Alternative decay parameters were tested empirically, with the relatively slow decay $\alpha=0.1$ selected as the best fit for the less highly concentrated rubber and plastics and metalworking machinery industries and the much faster decay $\alpha=1$ preferred for the more densely concentrated measuring and controlling devices industry. ${ }^{8}$

Labor pooling is measured as an establishment's access workers with skills that roughly match the industry's expected occupational requirements:

$$
L P_{k x}=\sum_{c}\left(\frac{O_{c x}}{O_{c T}} d_{c k}^{-\alpha}\right)
$$

where $x$ is the study industry, $c$ indexes counties, $k$ is the county of the target establishment, $O_{c x}$ is county $c$ 's residential workforce employed in the top 15 occupations employed by industry $x$ nationally, $O_{c T}$ is county c's total residential workforce, and $d_{c k}$ is the distance between county $c$ and the county of the target establishment, measured between county centroids, for distances of 75 miles or less and zero otherwise.

\footnotetext{
7 This particular problem is worsened in the present context by the urban nature of the industry samples; see below.

${ }^{8}$ The results presented in this paper are qualitatively robust to alternative distance decay specifications.
} 
Potential supply pools of manufactured inputs and producer services are calculated by weighting the local presence of supplier industries by the importance of each industry as a supplier to the study industry at the national level. Manufacturing input supply pooling is:

$$
S P_{k x}=\sum_{c}\left(\left(\sum_{m} \frac{E_{c m} P_{x m}}{P_{x M}}\right) \cdot d_{c k}^{-\alpha}\right)
$$

where $m$ indexes manufacturing industries, $x$ signifies the study industry, $c$ indexes counties, $k$ is the county of the target establishment, $E_{c m}$ is county $c$ 's employment in industry $m, P_{x m}$ is the dollar amount that the study industry purchases nationally from supplier industry $m, P_{x M}$ is the study industry's total national purchases from the manufacturing sector, and $d_{c k}$ is the same as for labor pooling. Producer services pooling has nearly the same formula except that purchases and local employment are totaled for suppliers of producer services:

$$
S D_{k x}=\sum_{c}\left(\left(\sum_{s} \frac{E_{c s} P_{x s}}{P_{x S}}\right) \cdot d_{c k}^{-\alpha}\right)
$$

where $s$ indexes producer services industries and $P_{x S}$ is the study industry's total national purchases of producer services.

Knowledge spillovers are typically proxied by input measures such as university research expenditures and the density of employment of scientists and engineers, or outcome measures such as patents or new inventions (Jaffe et al. 1993; Fritsch and Lukas 1999; Fritsch and Meschede 2001; Kirchhoff et al. 2002; Koo 2002). For this study, the relevant construct is access to potential sources of knowledge, rather than aggregate outcomes. The measure of potential labor pooling already accounts for the concentration of scientists and engineers. Two variables indicate different types of knowledge spillovers. The first gauges regional access to relevant basic research and knowledge:

$$
R S_{k x}=\sum_{c}\left(\left(\sum_{f} R_{c f}\right) \cdot d_{c k}^{-\alpha}\right)
$$

where $f$ indexes industry-relevant academic fields, $R_{c f}$ is the total amount of research expenditures in academic field $f$ during the previous five years at research universities located in county $c$, and the other variables are as in equations 2, 3, and 4. The maximum distance is 200 miles, since university-industry interactions in general need occur with less frequency and 
convenience than labor and supply interactions to have significant impacts upon firm practices (Matkin 1990; Tornatzky and Fleischer 1990).

Second, patenting provides an indication of the extent of private sector research activity and regional innovative culture. Many studies acknowledge faults with patents as a proxy for innovative activity, yet empirical research suggests that patents are related to the market value of knowledge, and in any case there are few viable alternatives (Jaffe 1989; Jaffe et al. 1993; Henderson et al. 1998; Acs et al. 2002; Agrawal and Cockburn 2003; Sampat et al. 2003). The patent measure weights the volume of patents in each technology classification by the relative importance of those technology categories to the target industry:

$$
P S_{r x}=\sum_{g \in K}\left(\frac{P A T_{g r}}{P O P_{r}} N_{g x}\right)
$$

where $g$ indexes patent technology classifications, $r$ signifies the region, $x$ represents the study industry, $K$ is the set of patent technology classifications relevant to the study industry (both directly and via cross-industry spillovers), $P A T_{g r}$ is the number of utility patents granted within region $r$ in the last five years in patent technology class $g, P O P_{r}$ is the regional residential population, and $N_{g x}$ is a measure of relevance derived from tabulations of patent citations. ${ }^{9}$

Additional Controls. A number of regional and establishment-level controls are included in the production function equation to account for additional characteristics that may impact productivity and agglomeration economies. Dummies identify establishments in firms that are either dominant (as classified for the regional industrial dominance measure), or small in that they report less than ten percent of the value of shipments of the smallest regional industry dominator firm. Dummy variables for Census Regions serve as proxies for different macroregional levels of development or macroeconomic conditions. Regional unemployment rates and median household income levels signal local economic conditions, and population density is included to help control for regional size, level of resources, and the absolute dimension of potential agglomeration economies, as well as urban congestion and other agglomeration diseconomies. ${ }^{10}$ A regional Herfindahl-Hirschman index calculated across 4-digit SIC industries

\footnotetext{
${ }^{9}$ Unlike the other four agglomeration variables, the patent measure incorporates geography solely in terms of regional boundaries; more precise geographic assignation of patents is problematic with publicly available data. 10 The percentage of resident adults with at least a bachelor's degree was originally included to indicate the regional human capital base, but it proved to be highly colinear with median household income.
} 
serves as an (inverse) measure of regional industrial diversity, controlling for "Jacobs externalities" that pertain within regions but across different industries.

Since the effects of regional industrial dominance or industrial diversity on establishment performance may be cumulative or otherwise persist over time, an historic version of each measure is included to help distinguish long-term effects. ${ }^{11}$ To avoid multicolinearity, historic dominance and historic diversity are included as the change in dominance or diversity from the historic period to the present, and only one historic measure for each of the two variables is included in the estimations.

Table 1 lists the full set of production function variables along with their sources.

\section{DESCRIPTIVE INFORMATION}

Table 2 describes the sets of establishments contained in the nine industry-year samples. The final sample sizes result from excluding observations in three categories: 1) administrative records for which most LRD data items are imputed; 2) non-positive input, output, or cost-share measures; and 3) plants located in regions with too few industry firms to consider regional industrial dominance meaningfully. Administrative records are by far the largest of these three categories. More than half of all the original LRD observations are in retained in the rubber and plastics (SIC 30) and metalworking machinery (SIC 354) industries, and slightly more than a third in measuring and controlling devices (SIC 382). The lower retention rate of measuring and controlling devices plants is due to a larger proportion of administrative records and a more concentrated geographic distribution that means that many of the plants not sited within a major agglomeration are located in regions with fewer than twelve industry firms.

There are several thousand plants in the rubber and plastics (SIC 30) and metalworking machinery (SIC 354) samples in each of the three study years. The measuring and controlling devices (SIC 382) samples are smaller but still contain more than 1,200 observations. The number of plants in each industry sample rises from 1992 to 1997 but falls substantially in 2002, victim of the continuing decline in manufacturing and the economic downturn of the early part of the new century. The sample sizes are quite large in the context of productivity estimation, supporting the translog production function with its large number of interaction terms.

\footnotetext{
${ }^{11}$ Each historic period is twenty years prior to the sample year, except that the historic diversity measure for the 1992 sample is from 1977.
} 
Table 1. Variables and Sources.

\begin{tabular}{lllll}
\hline Category & Variable & Description & Source \\
\hline dependent variable & Q & output & value of output & LRD \\
standard inputs & K & capital & gross book assets plus (capitalized) rentals & LRD \\
& L & labor & production-worker-equivalent hours & LRD \\
& E & energy & value of electricity and fuels & LRD \\
dominance & M & materials & value of purchased materials and services & LRD \\
agglomeration & D & dominance & percent of shipments in dominator firms & Census, BLS \\
economies & SP & labor pooling & percent of local employment in top industry occupations & LBD, BEA \\
& SD & producer services & local employment in producer service industries & LBD, BEA \\
& RS & research & university research expenditures in industry-relevant fields & NSF \\
& PS & patents & per capita industry-relevant patent rate & USPTO \\
controls & DE & dominator & dummy: establishment belongs to dominant firm & LRD \\
& SE & small & dummy: shipments less than 10 percent of smallest dominator & LRD \\
& CR1 & region & dummy: South Census Region & Census \\
& CR2 & region & dummy: Midwest Census Region & Census \\
& CR3 & region & dummy: West Census Region & Census \\
& POP & population & population density (persons per square mile) & Census \\
& UE & unemployment & unemployment rate & BLS \\
& INC & income & median household income in region (nominal dollars) & Census
\end{tabular}

LRD = Longitudinal Research Database, LBD = Longitudinal Business Database, BLS = Bureau of Labor Statistics (Staffing Patterns Matrix), BEA = Bureau of Economic Analysis (Benchmark Input-Output Accounts: Make and Use tables), NSF = National Science Foundation (CASPAR), USPTO = U.S. Patent and Trademark Office (Utility Patent Reports), Census = U.S. Bureau of the Census (decennial censes, population estimates, Small Area Income and Poverty Estimates ).

The mean plant sizes, whether measured by employment or shipment value, are not very large: less than 100 employees in SIC 30 and 382, and fewer than 40 employees in SIC 354. Average establishment sizes increase over the time frame of the samples, reflecting the trend of consolidation throughout the manufacturing sector. The plants retained in the final samples are larger in terms of employment or shipment value than those omitted, an additional reminder that the analysis is not representative of the very smallest manufacturers.

The fraction of plants classified as dominators ranges from approximately one in twelve in the 1992 metalworking machinery sample to about one in six in measuring and controlling devices in 2002. A higher percentage of establishments are part of relatively large firms in the later samples, again due to consolidation accompanying declining manufacturing employment. Of the non-dominator plants, roughly half are relatively small, with less than ten percent of the shipment value of the smallest dominator firm in their region, and the remaining establishments are not part of either dominator or dominated firms. Rubber and plastics establishments that are part of regional dominator firms on average have three to four times the employment and 
Table 2. Study Sample Characteristics.

\begin{tabular}{|c|c|c|c|c|c|c|c|c|c|}
\hline$\overline{\mathrm{SIC}}$ & & 30 & & & 354 & & & 382 & \\
\hline Industry & rubb & er \& plas & ics & metalwor & king mac & ninery & measuring \& & controllir & devices \\
\hline Year & 1992 & 1997 & 2002 & 1992 & 1997 & 2002 & 1992 & 1997 & 2002 \\
\hline Sample observations & 6,747 & 8,000 & 6,546 & 5,189 & 5,490 & 4,161 & 1,384 & 1,540 & 1,201 \\
\hline Dropped observations & 6,169 & 6,499 & 5,128 & 4,053 & 4,522 & 3,982 & 2,385 & 2,582 & 2,211 \\
\hline Percent retained in sample & 52.2 & 55.2 & 56.1 & 56.1 & 54.8 & 51.1 & 36.7 & 37.4 & 35.2 \\
\hline Mean employment & 78 & 82 & 91 & 33 & 38 & 36 & 97 & 94 & 111 \\
\hline Mean shipments & 9,912 & 12,789 & 16,259 & 3,417 & 5,191 & 5,185 & 12,891 & 17,603 & 22,393 \\
\hline Dominator establishments & 645 & 833 & 901 & 427 & 497 & 505 & 167 & 212 & 202 \\
\hline Percent & 9.6 & 10.4 & 13.8 & 8.2 & 9.1 & 12.1 & 12.1 & 13.8 & 16.8 \\
\hline Mean employment & 286 & 280 & 273 & 148 & 154 & 123 & 410 & 359 & 409 \\
\hline Mean shipments & 46,714 & 56,044 & 60,529 & 19,014 & 27,802 & 22,238 & 61,399 & 80,882 & 92,503 \\
\hline Dominated establishments & 3061 & 3701 & 2487 & 2686 & 2886 & 1846 & 658 & 687 & 505 \\
\hline Percent & 45.4 & 46.3 & 38.0 & 51.8 & 52.6 & 44.4 & 47.5 & 44.6 & 42.0 \\
\hline Mean employment & 23 & 24 & 26 & 13 & 15 & 15 & 21 & 23 & 23 \\
\hline Mean shipments & 1,835 & 2,254 & 2,835 & 964 & 1,462 & 1,562 & 1,958 & 2,800 & 3,056 \\
\hline Remainder of establishments & 3041 & 3466 & 3158 & 2076 & 2107 & 1810 & 559 & 641 & 494 \\
\hline Percent & 45.1 & 43.3 & 48.2 & 40.0 & 38.4 & 43.5 & 40.4 & 41.6 & 41.1 \\
\hline Mean emp & 89 & 97 & 91 & 36 & 41 & 34 & 93 & 82 & 80 \\
\hline Mean shipments & 10,236 & 13,642 & 14,199 & 3,384 & 4,966 & 4,122 & 11,269 & 12,540 & 13,491 \\
\hline
\end{tabular}

Note: Value of shipments reported in thousands of nominal dollars.

shipments of the average plant across all regions and are ten to twenty times the size of dominated plants, demonstrating the skewed nature of the establishment size distribution. The comparisons hold similarly for the other two study industries, with dominators averaging as much as twenty to thirty times larger than plants in small firms in the measuring and controlling devices industry.

All three study industries evidence substantial spatial concentration. The sample plants are located for the most part in urban and suburban counties, those within Metropolitan Statistical Areas (MSAs). This is partly due to the exclusion of plants in regions with fewer than twelve industry firms. Yet even in the full LRD dataset, most establishments in these industries are sited in metropolitan counties. The measuring and controlling devices industry has the most restricted geographic scope: only about ten percent of the LMA regions are represented in the estimation samples, with a substantial fraction of observations in a few populous East and West Coast counties. Sample establishments in the other two industries are spread across more than 100 regions. The spatial concentration of the samples can lead to problems: the fewer regions 
spanned, the less variation in regional measures and the greater tendency toward multicolinearity among the agglomeration variables and other regional indicators.

Table 3 reports the means, standard deviations, and, as an indicator of skewness, the percent of observations above the mean, for the model variables for the industry-year samples. ${ }^{12}$ The samples are skewed in terms of size: a large majority of plants have input and output quantities below the mean, and there is greater dispersion (i.e., a longer tail) on the large side of the size continuum. The regions surrounding the measuring and controlling device sample establishments tend to have greater household income, population density, and industrial diversity than the regions housing the other samples, further evidence of the geographic concentration of the industry in relatively dense and urbanized areas.

The largest portion of production costs in the rubber and plastics industry (SIC 30) is due to expenditures for materials. Labor costs predominate in the metalworking machinery industry (SIC 354), and the measuring and controlling devices industry (SIC 382) spends roughly equally on labor and materials, with those two factors constituting the majority of production costs. Energy is a only a small fraction of total production expenditures. Based on these indications, labor pooling advantages might be more important for metalworking machinery and measuring and controlling devices establishments than in the rubber and plastics industry. Indeed, rubber and plastics plants have the lowest average values for potential regional labor pooling, though, because the agglomeration measure is based on different occupations for each industry, it is not precisely comparable across industries. Knowledge spillovers presumably are most influential in higher technology industries; measuring and controlling device plants tend to be located in regions with average patenting rates three to five times greater than for the other two study industries. Although the other knowledge spillover measure appears to provide contradictory evidence, the larger mean proximate academic research figures in the rubber and plastics and metalworking machinery industries are due to the much gentler spatial decay with which the measure is calculated. For the same reason, it is not useful to contrast the supply pooling variables between measuring and controlling devices and the other two industries. ${ }^{13}$

\footnotetext{
${ }^{12}$ Confidentiality restrictions prevent reporting medians or other quantile measures.

13 The marked drop in the producer services variable in each study industry between 1992 and 1997 likely represents changed purchasing patterns and a shift in the input-output coding scheme more than altered regional availability of producer services. A modest increase in producer services follows from 1997 to 2002; the producer services variable uses identical purchasing matrices and coding systems for these two years. The inconsistency of variable
} 
Table 3. Variable Descriptive Information.

\begin{tabular}{|c|c|c|c|c|c|c|c|c|c|c|}
\hline \multicolumn{11}{|c|}{ SIC 30: Rubber and Plastics. } \\
\hline & & mean & std. dev. & $\%>\mathrm{mn}$ & mean & std. dev. & $\%>m n$ & mean & std. dev. & $\%>\mathrm{mn}$. \\
\hline $\mathrm{Q}$ & Output & 9,931 & 23,685 & 25.17 & 12,814 & 28,614 & 25.36 & 16,272 & 33,279 & 25.31 \\
\hline $\mathrm{K}$ & Capital & 4,856 & 16,606 & 21.73 & 6,286 & 19,748 & 22.16 & 9,166 & 24,751 & 22.53 \\
\hline $\mathrm{L}$ & Labor & 193 & 322 & 27.66 & 201 & 339 & 27.91 & 218 & 362 & 28.23 \\
\hline $\mathrm{E}$ & Energy & 18,997 & 54,866 & 22.62 & 22,199 & 64,385 & 21.93 & 28,054 & 81,757 & 21.77 \\
\hline M & Materials & 4,749 & 11,810 & 24.14 & 6,142 & 14,379 & 24.15 & 7,542 & 16,334 & 24.17 \\
\hline $\mathrm{C}_{\mathrm{K}}$ & Capital Cost Share & 13.82 & 8.01 & 39.91 & 17.81 & 9.28 & 48.56 & 21.13 & 10.23 & 46.62 \\
\hline $\mathrm{C}_{\mathrm{L}}$ & Labor Cost Share & 35.56 & 13.81 & 44.40 & 32.77 & 13.29 & 42.85 & 31.67 & 12.80 & 43.23 \\
\hline $\mathrm{C}_{\mathrm{E}}$ & Energy Cost Share & 2.89 & 2.32 & 38.34 & 2.39 & 1.92 & 34.91 & 2.35 & 1.93 & 36.80 \\
\hline $\mathrm{C}_{\mathrm{M}}$ & Materials Cost Share & 47.74 & 16.10 & 53.18 & 47.03 & 15.66 & 54.61 & 44.85 & 15.28 & 53.07 \\
\hline $\mathrm{D}$ & Dominance & 0.39 & 0.19 & 47.81 & 0.40 & 0.19 & 47.11 & 0.45 & 0.20 & 42.27 \\
\hline LP & Labor Pooling & 0.08 & 0.01 & 39.32 & 0.10 & 0.02 & 42.76 & 0.12 & 0.03 & 44.70 \\
\hline SP & Manufactured Inputs & 2,913 & 2,071 & 42.00 & 1,807 & 1,356 & 40.68 & 1,635 & 1,212 & 40.90 \\
\hline SD & Producer Services & 25,567 & 28,550 & 27.95 & 12,517 & 13,345 & 30.88 & 13,878 & 15,073 & 30.58 \\
\hline $\mathrm{RS}$ & Research & 330,729 & 242,436 & 38.94 & 406,037 & 274,997 & 41.69 & 501,543 & 322,954 & 41.87 \\
\hline PS & Patenting & 21.22 & 9.61 & 48.39 & 21.09 & 10.71 & 47.14 & 23.62 & 12.42 & 45.75 \\
\hline UE & Unemployment & 0.0714 & 0.0145 & 52.14 & 0.0443 & 0.0135 & 40.94 & 0.0566 & 0.0092 & 48.41 \\
\hline INC & Income & 36,028 & 4,655 & 44.60 & 41,339 & 5,606 & 46.95 & 45,419 & 6,902 & 47.63 \\
\hline POP & Population Density & 507.53 & 405.20 & 40.36 & 476.72 & 397.23 & 37.95 & 472.07 & 408.73 & 35.20 \\
\hline DV & Diversity & 0.0147 & 0.0037 & 37.02 & 0.0146 & 0.0043 & 37.51 & 0.0152 & 0.0055 & 32.29 \\
\hline DH & Historic Dominance & 0.58 & 0.21 & 44.79 & 0.55 & 0.22 & 48.79 & 0.49 & 0.24 & 46.52 \\
\hline DVH & Historic Diversity & 0.0139 & 0.0050 & 34.62 & 0.0149 & 0.0066 & 35.98 & 0.0161 & 0.0078 & 34.91 \\
\hline \multicolumn{5}{|c|}{ SIC 354: Metalworking Machinery. } & \multicolumn{3}{|c|}{$1997(\mathrm{n}=5,490)$} & \multicolumn{3}{|c|}{$2002(\mathrm{n}=4,161)$} \\
\hline Q & Output & $\begin{array}{l}\text { mean } \\
3,424\end{array}$ & $\begin{array}{r}\text { std. dev. } \\
11,539\end{array}$ & $\begin{array}{r}\%>\mathrm{mn} . \\
19.31\end{array}$ & $\begin{array}{l}\text { mean } \\
5,242\end{array}$ & $\begin{array}{r}\text { std. dev. } \\
19,903\end{array}$ & $\begin{array}{r}\%>\mathrm{mn} . \\
19.00\end{array}$ & $\begin{array}{l}\text { mean } \\
5,178\end{array}$ & $\begin{array}{r}\text { std. dev. } \\
18,096\end{array}$ & $\begin{array}{r}\%>\mathrm{mn} . \\
20.04\end{array}$ \\
\hline $\mathrm{K}$ & Capital & 1,922 & 5,236 & 21.56 & 2,597 & 7,039 & 21.44 & 3,526 & 8,676 & 23.34 \\
\hline $\mathrm{L}$ & Labor & 81 & 185 & 23.38 & 92 & 227 & 23.72 & 83 & 171 & 25.19 \\
\hline $\mathrm{E}$ & Energy & 3,528 & 13,700 & 18.87 & 4,211 & 16,225 & 20.56 & 4,174 & 13,135 & 20.60 \\
\hline M & Materials & 1,220 & 5,561 & 15.94 & 2,086 & 12,031 & 15.50 & 2,015 & 10,540 & 16.32 \\
\hline $\mathrm{C}_{\mathrm{K}}$ & Capital Cost Share & 8.78 & 5.03 & 37.75 & 12.90 & 7.00 & 45.12 & 14.25 & 7.46 & 38.84 \\
\hline $\mathrm{C}_{\mathrm{L}}$ & Labor Cost Share & 57.86 & 13.13 & 50.34 & 54.40 & 13.06 & 57.12 & 53.18 & 13.67 & 53.86 \\
\hline $\mathrm{C}_{\mathrm{E}}$ & Energy Cost Share & 1.65 & 1.29 & 38.12 & 1.43 & 1.37 & 34.94 & 1.36 & 1.35 & 33.60 \\
\hline $\mathrm{C}_{\mathrm{M}}$ & Materials Cost Share & 31.72 & 13.92 & 48.43 & 31.27 & 14.52 & 40.09 & 31.21 & 14.96 & 42.13 \\
\hline $\mathrm{D}$ & Dominance & 0.41 & 0.20 & 46.98 & 0.44 & 0.21 & 48.43 & 0.45 & 0.20 & 42.20 \\
\hline LP & Labor Pooling & 0.12 & 0.01 & 47.95 & 0.15 & 0.01 & 55.01 & 0.12 & 0.02 & 56.28 \\
\hline SP & Manufactured Inputs & 3,297 & 1,883 & 48.20 & 3,025 & 1,650 & 47.74 & 2,797 & 1,609 & 45.61 \\
\hline SD & Producer Services & 22,113 & 22,927 & 31.18 & 9,866 & 9,857 & 30.46 & 10,660 & 11,130 & 30.09 \\
\hline $\mathrm{RS}$ & Research & 497,467 & 377,447 & 38.95 & 725,256 & 475,313 & 39.69 & 924,617 & 555,602 & 44.20 \\
\hline PS & Patenting & 18.37 & 6.78 & 48.24 & 18.52 & 8.31 & 46.28 & 21.02 & 10.07 & 48.88 \\
\hline UE & Unemployment & 0.0752 & 0.0167 & 50.16 & 0.0426 & 0.0087 & 59.02 & 0.0575 & 0.0079 & 49.34 \\
\hline INC & Income & 36,088 & 4,365 & 48.66 & 41,967 & 4,961 & 51.69 & 45,518 & 6,091 & 48.91 \\
\hline POP & Population Density & 506.71 & 351.12 & 46.68 & 499.22 & 355.29 & 44.77 & 491.59 & 361.58 & 41.82 \\
\hline DV & Diversity & 0.0153 & 0.0038 & 42.57 & 0.0145 & 0.0035 & 49.31 & 0.0147 & 0.0047 & 46.14 \\
\hline DH & Historic Dominance & 0.49 & 0.22 & 50.43 & 0.51 & 0.20 & 53.61 & 0.49 & 0.20 & 52.75 \\
\hline DVH & Historic Diversity & 0.0153 & 0.0071 & 38.77 & 0.0156 & 0.0075 & 39.03 & 0.0157 & 0.0058 & 38.84 \\
\hline
\end{tabular}

construction across study years is unavoidable given the available secondary data, and does not affect the crosssectional analyses in this study. 
Table 3. Variable Descriptive Information, continued.

\begin{tabular}{|c|c|c|c|c|c|c|c|c|c|c|}
\hline \multirow{2}{*}{\multicolumn{2}{|c|}{ Year / Sample Size }} & \multicolumn{3}{|c|}{$1992(\mathrm{n}=1,384)$} & \multicolumn{3}{|c|}{$1997(\mathrm{n}=1,540)$} & \multicolumn{3}{|c|}{$2002(\mathrm{n}=1,201)$} \\
\hline & & mean & std. dev. & $\%>\mathrm{mn}$. & mean & std. dev. & $\%>\mathrm{mn}$. & mean & std. dev. & $\%>\mathrm{mn}$ \\
\hline Q & Output & 12,852 & 38,353 & 20.23 & 17,611 & 63,498 & 17.73 & 22,181 & 77,746 & 18.15 \\
\hline K & Capital & 4,744 & 15,682 & 18.50 & 5,854 & 25,133 & 17.47 & 8,880 & 33,063 & 16.82 \\
\hline $\mathrm{L}$ & Labor & 274 & 673 & 22.47 & 261 & 667 & 21.88 & 320 & 878 & 20.57 \\
\hline $\mathrm{E}$ & Energy & 7,787 & 24,120 & 17.05 & 8,065 & 29,751 & 17.27 & 9,039 & 33,750 & 16.74 \\
\hline M & Materials & 4,833 & 15,570 & 19.51 & 6,571 & 25,789 & 17.73 & 9,394 & 42,542 & 16.40 \\
\hline $\mathrm{C}_{\mathrm{K}}$ & Capital Cost Share & 10.27 & 6.43 & 33.38 & 13.46 & 7.43 & 47.08 & 14.12 & 7.92 & 44.88 \\
\hline $\mathrm{C}_{\mathrm{L}}$ & Labor Cost Share & 47.41 & 12.24 & 47.90 & 43.98 & 11.62 & 42.99 & 44.19 & 12.64 & 44.05 \\
\hline $\mathrm{C}_{\mathrm{E}}$ & Energy Cost Share & 1.16 & 1.06 & 40.53 & 1.02 & 1.28 & 32.60 & 0.83 & 0.80 & 30.97 \\
\hline $\mathrm{C}_{\mathrm{M}}$ & Materials Cost Share & 41.16 & 13.49 & 53.47 & 41.54 & 13.74 & 56.04 & 40.86 & 14.65 & 56.37 \\
\hline $\mathrm{D}$ & Dominance & 0.54 & 0.18 & 44.51 & 0.59 & 0.15 & 45.52 & 0.64 & 0.14 & 38.38 \\
\hline LP & Labor Pooling & 0.14 & 0.02 & 39.45 & 0.20 & 0.03 & 42.53 & 0.15 & 0.03 & 40.88 \\
\hline SP & Manufactured Inputs & 1,728 & 2,167 & 25.22 & 2,374 & 4,113 & 18.31 & 2,051 & 3,194 & 22.90 \\
\hline SD & Producer Services & 7,089 & 4,425 & 50.51 & 4,401 & 3,039 & 47.79 & 5,268 & 3,809 & 46.54 \\
\hline RS & Research & 160,186 & 229,831 & 22.90 & 185,002 & 267,781 & 29.48 & 201,325 & 261,265 & 27.81 \\
\hline PS & Patenting & 61.57 & 24.77 & 40.25 & 72.12 & 39.13 & 32.21 & 96.29 & 70.24 & 35.97 \\
\hline UE & Unemployment & 0.0731 & 0.0133 & 57.30 & 0.0431 & 0.0084 & 47.14 & 0.0575 & 0.0105 & 40.97 \\
\hline INC & Income & 39,442 & 4,448 & 53.18 & 45,485 & 5,234 & 54.29 & 51,215 & 6,751 & 48.38 \\
\hline POP & Population Density & 681.93 & 390.05 & 45.66 & 677.29 & 390.98 & 42.34 & 698.59 & 396.70 & 42.63 \\
\hline DV & Diversity & 0.0134 & 0.0019 & 39.60 & 0.0130 & 0.0021 & 26.75 & 0.0131 & 0.0024 & 44.96 \\
\hline DH & Historic Dominance & 0.74 & 0.16 & 51.73 & 0.70 & 0.17 & 41.30 & 0.65 & 0.18 & 42.38 \\
\hline DVH & Historic Diversity & 0.0126 & 0.0031 & 36.13 & 0.0127 & 0.0035 & 35.71 & 0.0134 & 0.0032 & 40.30 \\
\hline
\end{tabular}

Note: Output, capital, and materials in thousands of nominal dollars; labor in thousands of hours; energy in millions of BTUs.

The five agglomeration economy variables are mainly positively correlated with each other, as expected, but possess sufficient independent variation for regression analysis (Table 4). The correlation coefficients between academic research and manufactured inputs supply pooling for rubber and plastics manufactures, and between the two supply pooling measures for all three industries, are high enough that the estimated coefficients should be evaluated with caution.

Dominance is negatively correlated, though not excessively so, with most of the agglomeration economy variables, since larger and denser regions both provide more potential agglomeration economies and are less likely to be dominated.

\section{RESULTS}

The system of four equations defined by equation (1) and three associated cost share equations is estimated separately for each of the nine cross-sections defined by the three study industries and three years of data. Histograms and normal quantile plots confirm the approximate normality of the residuals. Alternative starting values used to test model convergence demonstrate that the optima are not global but are robust within a large domain. Breusch-Pagan tests yield inconsistent results, but heteroskedasticity-corrected standard errors do 
Table 4. Pearson Pairwise Correlation Coefficients Among Key Independent Variables.

\begin{tabular}{|c|c|c|c|c|c|c|c|c|c|c|c|c|c|c|c|c|}
\hline \multicolumn{7}{|c|}{ SIC 30: Rubber and Plastics. } & \multicolumn{5}{|c|}{1997} & \multicolumn{5}{|c|}{2002} \\
\hline$(\mathrm{D}=$ Dominance $)$ & & $\mathrm{D}$ & LP & SP & SD & $\mathrm{RS}$ & $\mathrm{D}$ & $\mathrm{LP}$ & SP & SD & $\overline{\mathrm{RS}}$ & $\mathrm{D}$ & LP & SP & SD & $\overline{\mathrm{RS}}$ \\
\hline Labor Pooling & LP & 0.2142 & & & & & 0.1063 & & & & & 0.1767 & & & & \\
\hline Manufactured Inputs & SP & -0.4955 & 0.1577 & & & & -0.4129 & 0.0207 & & & & -0.4847 & -0.0144 & & & \\
\hline Producer Services & SD & -0.5523 & -0.5016 & 0.6712 & & & -0.5232 & -0.4764 & 0.7617 & & & -0.5457 & -0.5395 & 0.7651 & & \\
\hline Research & $\mathrm{RS}$ & -0.2871 & 0.1602 & 0.7670 & 0.4983 & & -0.2562 & 0.1587 & 0.6757 & 0.4362 & & -0.2687 & 0.1165 & 0.6861 & 0.4470 & \\
\hline Patenting & PS & -0.5430 & -0.0479 & 0.4774 & 0.3651 & 0.3492 & -0.4843 & 0.0167 & 0.4200 & 0.3910 & 0.2913 & -0.5128 & -0.0215 & 0.4486 & 0.3687 & 0.3085 \\
\hline \multicolumn{17}{|c|}{ SIC 354: Metalworking Machinery. } \\
\hline$(\mathrm{D}=$ Dominance $)$ & & $\mathrm{D}$ & LP & SP & SD & $\overline{\mathrm{RS}}$ & $\mathrm{D}$ & LP & SP & $\mathrm{SD}$ & $\overline{\mathrm{RS}}$ & $\mathrm{D}$ & LP & $\mathrm{SP}$ & $\mathrm{SD}$ & RS \\
\hline Labor Pooling & LP & -0.4933 & & & & & -0.3019 & & & & & -0.2915 & & & & \\
\hline Manufactured Inputs & SP & -0.4218 & 0.6153 & & & & -0.4630 & 0.3716 & & & & -0.5537 & 0.1527 & & & \\
\hline Producer Services & SD & -0.3490 & 0.0638 & 0.6214 & & & -0.3555 & -0.3327 & 0.6482 & & & -0.2490 & -0.5148 & 0.6486 & & \\
\hline Research & $\mathrm{RS}$ & -0.0632 & 0.0014 & 0.5203 & 0.4767 & & -0.1124 & 0.0701 & 0.5551 & 0.3628 & & -0.2193 & 0.0081 & 0.5523 & 0.3291 & \\
\hline Patenting & PS & -0.5252 & 0.5222 & 0.4350 & 0.2830 & 0.0577 & -0.5975 & 0.2635 & 0.4670 & 0.3422 & 0.0435 & -0.5470 & 0.1596 & 0.4547 & 0.3125 & -0.0216 \\
\hline \multicolumn{17}{|c|}{ SIC 382: Measuring and Controlling Devices. } \\
\hline$(\mathrm{D}=$ Dominance $)$ & & $\mathrm{D}$ & LP & SP & SD & $\overline{\mathrm{RS}}$ & $\mathrm{D}$ & LP & SP & SD & $\overline{\mathrm{RS}}$ & $\mathrm{D}$ & $\mathrm{LP}$ & SP & SD & $\overline{\mathrm{RS}}$ \\
\hline Labor Pooling & LP & -0.2926 & & & & & -0.2020 & & & & & -0.0506 & & & & \\
\hline Manufactured Inputs & SP & -0.3989 & 0.6064 & & & & -0.2781 & 0.6540 & & & & -0.2238 & 0.5817 & & & \\
\hline Producer Services & SD & -0.2874 & 0.1661 & 0.6837 & & & -0.1804 & 0.2071 & 0.6576 & & & -0.2064 & 0.1074 & 0.6891 & & \\
\hline Research & $\mathrm{RS}$ & -0.5207 & 0.2686 & 0.6529 & 0.5253 & & -0.4722 & 0.3120 & 0.6200 & 0.5239 & & -0.3243 & 0.3308 & 0.5937 & 0.5285 & \\
\hline Patenting & PS & -0.5366 & 0.5319 & 0.5230 & 0.1252 & 0.3936 & -0.4718 & 0.5748 & 0.5531 & 0.0990 & 0.4006 & -0.3568 & 0.6622 & 0.5705 & 0.1545 & 0.4439 \\
\hline
\end{tabular}

Note: Correlations measured with natural logarithms of all agglomeration variables except for labor pooling. 
not alter the substantive results of the analysis. Checks of monotonicity and convexity suggest that these required economic regularities are satisfied in the vicinity of the point of approximation but that caution is warranted in applying the results to distant points in the sample space. Tests of common model simplifications are carried out and rejected (see Appendix C). As is standard in cross-sectional work, the final estimated parameters are interpreted to represent a long-run equilibrium. The parameter estimates, asymptotic standard errors, and associated probability values are reported in Tables 5, 6, and 7.

Standard Inputs and Control Variables. The coefficients of the standard inputs and cross-terms (the $\alpha$ and $\beta$ terms) display the expected signs: production is positively related to input quantities, and negative cross-products indicate input substitution in each model. ${ }^{14}$ Population density has consistently positive effects on productivity, suggesting that urban economies outweigh congestion and other diseconomies of density. The magnitude of the influence is quite small in practical terms. It would require an increase in population density of more than 13 percent to raise average output by one percent for measuring and controlling devices plants in 2002, and even greater increases in the other models.

There is much variability in the influence of income, unemployment, and industrial diversity, and the macro-regional dummy variables. Higher regional median household incomes are associated with greater productivity in the rubber and plastics industry, where income may indicate local workforce skills, but with lower production in the other two study industries. Labor's average share of production cost is larger for metalworking machinery and measuring and controlling device establishments, so perhaps higher wage costs outweigh skill advantages. Differing macroeconomic climates may partially explain the variation in the effect of unemployment over time, but the unevenness across industries suggests industry-specific associations with establishment-level production.

The estimated coefficients of industrial diversity are relatively large and negative in the measuring and controlling devices and metalworking machinery industries, suggesting Jacobs externality benefits from cross-industry knowledge or technology spillovers. ${ }^{15}$ The rubber and

\footnotetext{
${ }^{14}$ Note that this is only a face-value examination of the direct coefficient estimates. Partial elasticity measures, such as Morishima or Allen elasticities, are typically employed to evaluate empirical input substitution (Chambers 1988; Blackorby and Russell 1989). Frondel and Schmidt (2002) argue that substitution elasticities are driven by factor shares in the translog framework and thus are not very informative.

${ }^{15}$ Recall that the measure of industrial diversity is inverted, so that negative coefficients indicate a productivity benefit to being located in a more industrially diverse region.
} 
Table 5. Parameter Estimates for Rubber and Plastics (SIC 30).

\begin{tabular}{|c|c|c|c|c|c|c|c|c|c|c|}
\hline \multirow{2}{*}{$\begin{array}{l}\text { Year } \\
\text { Variable }\end{array}$} & \multirow[b]{2}{*}{ Param. } & \multicolumn{3}{|c|}{1992} & \multicolumn{3}{|c|}{1997} & \multicolumn{3}{|c|}{2002} \\
\hline & & Coeff. & td. Err. & p Value & Coeff. & Std. Err. & p Value & Coeff. & Std. Err. & $\mathrm{p}$ Value \\
\hline constant & $\alpha_{0}$ & 8.278 & 0.011 & 0.00 & 8.436 & 0.011 & 0.00 & 8.788 & 0.012 & 0.00 \\
\hline $\ln K$ & $\alpha_{k}$ & 0.130 & 0.001 & 0.00 & 0.168 & 0.001 & 0.00 & 0.198 & 0.001 & 0.00 \\
\hline $\ln \mathrm{L}$ & $\alpha_{l}$ & 0.334 & 0.002 & 0.00 & 0.308 & 0.001 & 0.00 & 0.298 & 0.002 & 0.00 \\
\hline $\ln E$ & $\alpha_{e}$ & 0.027 & 0.000 & 0.00 & 0.023 & 0.000 & 0.00 & 0.022 & 0.000 & 0.00 \\
\hline $\ln M$ & $\alpha_{m}$ & 0.447 & 0.002 & 0.00 & 0.443 & 0.002 & 0.00 & 0.418 & 0.002 & 0.00 \\
\hline$(\ln K)^{2}$ & $\beta_{k k}$ & 0.085 & 0.001 & 0.00 & 0.096 & 0.001 & 0.00 & 0.102 & 0.001 & 0.00 \\
\hline$(\ln L)^{2}$ & $\beta_{l l}$ & 0.142 & 0.002 & 0.00 & 0.138 & 0.001 & 0.00 & 0.119 & 0.001 & 0.00 \\
\hline$(\ln E)^{2}$ & $\beta_{e e}$ & 0.019 & 0.000 & 0.00 & 0.017 & 0.000 & 0.00 & 0.016 & 0.000 & 0.00 \\
\hline$(\ln \mathrm{M})^{2}$ & $\beta_{m m}$ & 0.172 & 0.001 & 0.00 & 0.179 & 0.001 & 0.00 & 0.157 & 0.001 & 0.00 \\
\hline $\ln \mathrm{K} \cdot \ln \mathrm{L}$ & $\beta_{k l}$ & -0.032 & 0.001 & 0.00 & -0.033 & 0.001 & 0.00 & -0.038 & 0.001 & 0.00 \\
\hline $\ln \mathrm{K} \cdot \ln \mathrm{E}$ & $\beta_{k e}$ & -0.003 & 0.000 & 0.00 & -0.002 & 0.000 & 0.00 & -0.003 & 0.000 & 0.00 \\
\hline $\ln \mathrm{K} \cdot \ln \mathrm{M}$ & $\beta_{k m}$ & -0.056 & 0.001 & 0.00 & -0.067 & 0.001 & 0.00 & -0.073 & 0.001 & 0.00 \\
\hline $\ln \mathrm{L} \cdot \ln \mathrm{E}$ & $\beta_{l e}$ & -0.005 & 0.000 & 0.00 & -0.005 & 0.000 & 0.00 & -0.003 & 0.000 & 0.00 \\
\hline $\ln \mathrm{L} \cdot \ln \mathrm{M}$ & $\beta_{l m}$ & -0.114 & 0.001 & 0.00 & -0.108 & 0.001 & 0.00 & -0.094 & 0.001 & 0.00 \\
\hline $\ln \mathrm{E} \cdot \ln \mathrm{M}$ & $\beta_{\text {em }}$ & -0.012 & 0.000 & 0.00 & -0.010 & 0.000 & 0.00 & -0.011 & 0.000 & 0.00 \\
\hline D & $\gamma_{d}$ & -0.045 & 0.039 & 0.25 & -0.051 & 0.033 & 0.12 & -0.065 & 0.037 & 0.08 \\
\hline LP & $\gamma_{l p}$ & 0.900 & 0.593 & 0.13 & 0.040 & 0.324 & 0.90 & 0.686 & 0.344 & 0.05 \\
\hline $\ln \mathrm{SP}$ & $\gamma_{s p}$ & 0.005 & 0.013 & 0.67 & 0.000 & 0.011 & 0.98 & -0.011 & 0.013 & 0.41 \\
\hline $\ln \mathrm{SD}$ & $\gamma_{s d}$ & -0.005 & 0.012 & 0.66 & 0.000 & 0.012 & 0.97 & 0.016 & 0.013 & 0.22 \\
\hline $\ln \mathrm{RS}$ & $\gamma_{r s}$ & 0.002 & 0.009 & 0.86 & 0.007 & 0.007 & 0.32 & 0.005 & 0.008 & 0.50 \\
\hline $\ln$ PS & $\gamma_{p s}$ & 0.003 & 0.012 & 0.81 & 0.020 & 0.010 & 0.04 & 0.021 & 0.011 & 0.07 \\
\hline$D^{2}$ & $\delta_{d d}$ & -0.451 & 0.259 & 0.08 & -0.301 & 0.215 & 0.16 & -1.057 & 0.263 & 0.00 \\
\hline $\mathrm{D} \cdot \mathrm{LP}$ & $\delta_{d l p}$ & 0.372 & 2.754 & 0.89 & -1.368 & 1.030 & 0.18 & -0.850 & 1.283 & 0.51 \\
\hline $\mathrm{D} \cdot \ln \mathrm{SP}$ & $\delta_{d s p}$ & 0.024 & 0.061 & 0.69 & 0.035 & 0.045 & 0.44 & 0.014 & 0.053 & 0.80 \\
\hline $\mathrm{D} \cdot \ln \mathrm{SD}$ & $\delta_{d s d}$ & -0.046 & 0.051 & 0.37 & -0.044 & 0.043 & 0.30 & -0.106 & 0.051 & 0.04 \\
\hline $\mathrm{D} \cdot \ln \mathrm{RS}$ & $\delta_{d r s}$ & 0.039 & 0.037 & 0.29 & 0.041 & 0.028 & 0.14 & 0.033 & 0.035 & 0.34 \\
\hline $\mathrm{D} \cdot \ln \mathrm{PS}$ & $\delta_{d p s}$ & -0.061 & 0.045 & 0.18 & -0.014 & 0.038 & 0.72 & -0.123 & 0.040 & 0.00 \\
\hline$D \cdot \ln K$ & $\lambda_{d k}$ & 0.021 & 0.004 & 0.00 & 0.006 & 0.003 & 0.07 & 0.012 & 0.005 & 0.01 \\
\hline $\mathrm{D} \cdot \ln \mathrm{L}$ & $\lambda_{d l}$ & 0.027 & 0.008 & 0.00 & -0.003 & 0.006 & 0.62 & 0.023 & 0.007 & 0.00 \\
\hline$D \cdot \ln E$ & $\lambda_{d e}$ & 0.001 & 0.001 & 0.35 & -0.002 & 0.001 & 0.01 & 0.001 & 0.001 & 0.46 \\
\hline $\mathrm{D} \cdot \ln \mathrm{M}$ & $\lambda_{d m}$ & 0.035 & 0.008 & 0.00 & -0.006 & 0.006 & 0.31 & 0.017 & 0.008 & 0.03 \\
\hline
\end{tabular}


Table 5. Parameter Estimates for Rubber and Plastics (SIC 30), continued.

\begin{tabular}{|c|c|c|c|c|c|c|c|c|c|c|}
\hline \multirow{2}{*}{$\begin{array}{l}\text { Year } \\
\text { Variable }\end{array}$} & \multirow[b]{2}{*}{ Param. } & \multicolumn{3}{|c|}{1992} & \multicolumn{3}{|c|}{1997} & \multicolumn{3}{|c|}{2002} \\
\hline & & Coeff. & Std. Err. & p Value & Coeff." & Std. Err. & p Value & Coeff." & Std. Err. & p Value \\
\hline $\mathrm{LP} \cdot \ln \mathrm{K}$ & $\lambda_{l p k}$ & -0.082 & 0.072 & 0.25 & 0.025 & 0.034 & 0.46 & 0.159 & 0.044 & 0.00 \\
\hline $\mathrm{LP} \cdot \ln \mathrm{L}$ & $\lambda_{l p l}$ & 0.056 & 0.152 & 0.71 & -0.105 & 0.057 & 0.06 & 0.078 & 0.067 & 0.25 \\
\hline $\mathrm{LP} \cdot \ln \mathrm{E}$ & $\lambda_{\text {lpe }}$ & -0.093 & 0.028 & 0.00 & -0.070 & 0.009 & 0.00 & -0.067 & 0.010 & 0.00 \\
\hline$L P \cdot \ln M$ & $\lambda_{l p m}$ & 0.083 & 0.165 & 0.61 & 0.119 & 0.062 & 0.06 & 0.380 & 0.073 & 0.00 \\
\hline $\ln \mathrm{SP} \cdot \ln \mathrm{K}$ & $\lambda_{s p k}$ & 0.004 & 0.002 & 0.02 & 0.003 & 0.001 & 0.01 & 0.001 & 0.002 & 0.57 \\
\hline $\ln \mathrm{SP} \cdot \ln \mathrm{L}$ & $\lambda_{s p l}$ & 0.000 & 0.003 & 0.97 & 0.000 & 0.002 & 0.88 & -0.002 & 0.003 & 0.61 \\
\hline $\ln \mathrm{SP} \cdot \ln \mathrm{E}$ & $\lambda_{s p e}$ & 0.001 & 0.001 & 0.11 & 0.000 & 0.000 & 0.67 & 0.000 & 0.000 & 0.36 \\
\hline $\ln \mathrm{SP} \cdot \ln \mathrm{M}$ & $\lambda_{s p m}$ & 0.014 & 0.003 & 0.00 & 0.000 & 0.003 & 0.90 & 0.003 & 0.003 & 0.32 \\
\hline $\ln \mathrm{SD} \cdot \ln \mathrm{K}$ & $\lambda_{s d k}$ & -0.002 & 0.001 & 0.10 & -0.004 & 0.001 & 0.01 & 0.001 & 0.002 & 0.68 \\
\hline $\ln \mathrm{SD} \cdot \ln \mathrm{L}$ & $\lambda_{s d l}$ & 0.007 & 0.003 & 0.02 & 0.001 & 0.002 & 0.66 & 0.005 & 0.003 & 0.08 \\
\hline $\ln \mathrm{SD} \cdot \ln \mathrm{E}$ & $\lambda_{s d e}$ & 0.001 & 0.001 & 0.06 & 0.000 & 0.000 & 0.57 & 0.000 & 0.000 & 0.30 \\
\hline $\ln \mathrm{SD} \cdot \ln \mathrm{M}$ & $\lambda_{s d m}$ & -0.007 & 0.003 & 0.02 & -0.003 & 0.003 & 0.24 & 0.003 & 0.003 & 0.36 \\
\hline $\ln \mathrm{RS} \cdot \ln \mathrm{K}$ & $\lambda_{r s k}$ & -0.001 & 0.001 & 0.49 & 0.002 & 0.001 & 0.04 & 0.002 & 0.001 & 0.04 \\
\hline $\ln \mathrm{RS} \cdot \ln \mathrm{L}$ & $\lambda_{r s l}$ & 0.003 & 0.002 & 0.13 & 0.003 & 0.001 & 0.01 & 0.003 & 0.002 & 0.08 \\
\hline $\ln \mathrm{RS} \cdot \ln \mathrm{E}$ & $\lambda_{r s e}$ & 0.001 & 0.000 & 0.00 & 0.002 & 0.000 & 0.00 & 0.002 & 0.000 & 0.00 \\
\hline $\ln \mathrm{RS} \cdot \ln \mathrm{M}$ & $\lambda_{r s m}$ & -0.007 & 0.002 & 0.00 & 0.002 & 0.001 & 0.24 & -0.001 & 0.002 & 0.50 \\
\hline $\ln \mathrm{PS} \cdot \ln \mathrm{K}$ & $\lambda_{p s k}$ & 0.002 & 0.001 & 0.22 & -0.003 & 0.001 & 0.01 & 0.000 & 0.002 & 0.99 \\
\hline $\ln \mathrm{PS} \cdot \ln \mathrm{L}$ & $\lambda_{p s l}$ & 0.007 & 0.003 & 0.01 & 0.008 & 0.002 & 0.00 & 0.011 & 0.002 & 0.00 \\
\hline $\ln \mathrm{PS} \cdot \ln \mathrm{E}$ & $\lambda_{\text {pse }}$ & 0.000 & 0.000 & 0.57 & 0.000 & 0.000 & 0.33 & 0.001 & 0.000 & 0.03 \\
\hline $\ln \mathrm{PS} \cdot \ln \mathrm{M}$ & $\lambda_{p s m}$ & -0.007 & 0.003 & 0.01 & -0.009 & 0.002 & 0.00 & -0.004 & 0.003 & 0.10 \\
\hline $\mathrm{DE}$ & $v_{d e}$ & 0.141 & 0.013 & 0.00 & 0.149 & 0.012 & 0.00 & 0.192 & 0.013 & 0.00 \\
\hline SE & $v_{s e}$ & -0.191 & 0.010 & 0.00 & -0.174 & 0.009 & 0.00 & -0.159 & 0.010 & 0.00 \\
\hline CR1 & $v_{c r l}$ & -0.019 & 0.015 & 0.19 & 0.018 & 0.012 & 0.13 & 0.001 & 0.015 & 0.94 \\
\hline CR2 & $v_{c r 2}$ & -0.004 & 0.013 & 0.74 & 0.003 & 0.014 & 0.82 & -0.013 & 0.016 & 0.39 \\
\hline CR3 & $v_{c r 3}$ & -0.023 & 0.017 & 0.19 & -0.002 & 0.015 & 0.90 & -0.018 & 0.020 & 0.35 \\
\hline $\ln \mathrm{POP}$ & $v_{p o p}$ & 0.024 & 0.008 & 0.00 & 0.006 & 0.007 & 0.38 & 0.001 & 0.008 & 0.92 \\
\hline UE & $v_{u e}$ & -0.485 & 0.307 & 0.11 & 0.683 & 0.287 & 0.02 & -0.251 & 0.487 & 0.61 \\
\hline $\ln$ INC & $v_{i n c}$ & 0.139 & 0.051 & 0.01 & 0.095 & 0.043 & 0.03 & 0.090 & 0.046 & 0.05 \\
\hline DV & $v_{d v}$ & 1.609 & 1.112 & 0.15 & -1.494 & 0.852 & 0.08 & 0.554 & 0.816 & 0.50 \\
\hline DH & $\rho_{d h}$ & -0.012 & 0.028 & 0.67 & -0.002 & 0.026 & 0.94 & -0.060 & 0.035 & 0.09 \\
\hline DVH & $\rho_{d v h}$ & -0.148 & 0.961 & 0.88 & -0.349 & 0.581 & 0.55 & 0.735 & 0.655 & 0.26 \\
\hline \multicolumn{3}{|c|}{ Generalized $\mathrm{R}^{2}$} & & 0.999 & & & 0.999 & & & 0.999 \\
\hline \multicolumn{11}{|c|}{ Equation Adjusted $\mathrm{R}^{2}$} \\
\hline \multicolumn{3}{|c|}{ Production Function } & & 0.942 & & & 0.952 & & & 0.935 \\
\hline \multicolumn{2}{|c|}{ Capital Cost Share } & & & 0.761 & & & 0.758 & & & 0.754 \\
\hline \multicolumn{2}{|c|}{ Labor Cost Share } & & & 0.745 & & & 0.739 & & & 0.737 \\
\hline \multicolumn{2}{|c|}{ Materials Cost Share } & & & 0.851 & & & 0.878 & & & 0.858 \\
\hline
\end{tabular}


Table 6. Parameter Estimates for Metalworking Machinery (SIC 354).

\begin{tabular}{|c|c|c|c|c|c|c|c|c|c|c|}
\hline \multirow{3}{*}{$\begin{array}{l}\text { Year } \\
\text { Variable } \\
\text { constant }\end{array}$} & \multirow{3}{*}{$\begin{array}{l}\text { Param. } \\
\alpha_{0}\end{array}$} & \multicolumn{3}{|c|}{1992} & \multicolumn{3}{|c|}{1997} & \multicolumn{3}{|c|}{2002} \\
\hline & & Coeff. & Std. Err. & p Value & Coeff. & Std. Err. & p Value & Coeff. & Std. Err. & p Value \\
\hline & & 7.152 & 0.014 & 0.00 & 7.382 & 0.016 & 0.00 & 7.560 & 0.017 & 0.00 \\
\hline $\ln \mathrm{K}$ & $\alpha_{k}$ & 0.085 & 0.001 & 0.00 & 0.124 & 0.001 & 0.00 & 0.135 & 0.001 & 0.00 \\
\hline $\ln \mathrm{L}$ & $\alpha_{l}$ & 0.562 & 0.003 & 0.00 & 0.520 & 0.002 & 0.00 & 0.505 & 0.003 & 0.00 \\
\hline $\ln \mathrm{E}$ & $\alpha_{e}$ & 0.016 & 0.000 & 0.00 & 0.014 & 0.000 & 0.00 & 0.013 & 0.000 & 0.00 \\
\hline $\ln M$ & $\alpha_{m}$ & 0.308 & 0.002 & 0.00 & 0.300 & 0.001 & 0.00 & 0.294 & 0.002 & 0.00 \\
\hline$(\ln K)^{2}$ & $\beta_{k k}$ & 0.064 & 0.001 & 0.00 & 0.080 & 0.001 & 0.00 & 0.080 & 0.001 & 0.00 \\
\hline$(\ln L)^{2}$ & $\beta_{l l}$ & 0.183 & 0.002 & 0.00 & 0.175 & 0.002 & 0.00 & 0.141 & 0.002 & 0.00 \\
\hline$(\ln E)^{2}$ & $\beta_{e e}$ & 0.013 & 0.000 & 0.00 & 0.013 & 0.000 & 0.00 & 0.011 & 0.000 & 0.00 \\
\hline$(\ln M)^{2}$ & $\beta_{m m}$ & 0.170 & 0.001 & 0.00 & 0.174 & 0.001 & 0.00 & 0.154 & 0.001 & 0.00 \\
\hline $\ln \mathrm{K} \cdot \ln \mathrm{L}$ & $\beta_{k l}$ & -0.038 & 0.001 & 0.00 & -0.046 & 0.001 & 0.00 & -0.047 & 0.001 & 0.00 \\
\hline $\ln \mathrm{K} \cdot \ln \mathrm{E}$ & $\beta_{k e}$ & -0.001 & 0.000 & 0.00 & -0.001 & 0.000 & 0.00 & -0.001 & 0.000 & 0.00 \\
\hline $\ln \mathrm{K} \cdot \ln \mathrm{M}$ & $\beta_{k m}$ & -0.029 & 0.000 & 0.00 & -0.038 & 0.001 & 0.00 & -0.040 & 0.001 & 0.00 \\
\hline $\ln \mathrm{L} \cdot \ln \mathrm{E}$ & $\beta_{l e}$ & -0.006 & 0.000 & 0.00 & -0.006 & 0.000 & 0.00 & -0.005 & 0.000 & 0.00 \\
\hline $\ln \mathrm{L} \cdot \ln \mathrm{M}$ & $\beta_{l m}$ & -0.140 & 0.001 & 0.00 & -0.131 & 0.001 & 0.00 & -0.119 & 0.001 & 0.00 \\
\hline $\ln \mathrm{E} \cdot \ln \mathrm{M}$ & $\beta_{e m}$ & -0.006 & 0.000 & 0.00 & -0.006 & 0.000 & 0.00 & -0.006 & 0.000 & 0.00 \\
\hline $\mathrm{D}$ & $\gamma_{d}$ & -0.088 & 0.041 & 0.03 & -0.200 & 0.041 & 0.00 & -0.190 & 0.052 & 0.00 \\
\hline LP & $\gamma_{l p}$ & -0.512 & 0.973 & 0.60 & -2.826 & 0.936 & 0.00 & 0.060 & 0.630 & 0.92 \\
\hline $\ln \mathrm{SP}$ & $\gamma_{s p}$ & 0.024 & 0.017 & 0.15 & 0.030 & 0.018 & 0.09 & -0.040 & 0.018 & 0.03 \\
\hline $\ln \mathrm{SD}$ & $\gamma_{s d}$ & -0.012 & 0.013 & 0.36 & -0.046 & 0.016 & 0.00 & 0.025 & 0.017 & 0.14 \\
\hline $\ln \mathrm{RS}$ & $\gamma_{r s}$ & -0.029 & 0.010 & 0.00 & 0.005 & 0.011 & 0.65 & -0.019 & 0.011 & 0.08 \\
\hline $\ln \mathrm{PS}$ & $\gamma_{p s}$ & 0.076 & 0.017 & 0.00 & 0.083 & 0.015 & 0.00 & 0.106 & 0.017 & 0.00 \\
\hline $\mathrm{D}^{2}$ & $\delta_{d d}$ & 0.287 & 0.287 & 0.32 & 0.821 & 0.277 & 0.00 & -0.052 & 0.328 & 0.87 \\
\hline $\mathrm{D} \cdot \mathrm{LP}$ & $\delta_{d l p}$ & -1.368 & 4.734 & 0.77 & -2.749 & 3.265 & 0.40 & 0.801 & 2.585 & 0.76 \\
\hline $\mathrm{D} \cdot \ln \mathrm{SP}$ & $\delta_{d s p}$ & -0.095 & 0.080 & 0.23 & 0.023 & 0.085 & 0.79 & -0.099 & 0.084 & 0.24 \\
\hline $\mathrm{D} \cdot \ln \mathrm{SD}$ & $\delta_{d s d}$ & 0.051 & 0.050 & 0.30 & 0.041 & 0.060 & 0.49 & 0.132 & 0.073 & 0.07 \\
\hline$D \cdot \ln R S$ & $\delta_{d r s}$ & 0.013 & 0.037 & 0.73 & -0.040 & 0.037 & 0.27 & -0.018 & 0.044 & 0.68 \\
\hline $\mathrm{D} \cdot \ln \mathrm{PS}$ & $\delta_{d p s}$ & 0.035 & 0.076 & 0.65 & 0.029 & 0.057 & 0.62 & -0.121 & 0.068 & 0.07 \\
\hline $\mathrm{D} \cdot \ln \mathrm{K}$ & $\lambda_{d k}$ & 0.004 & 0.003 & 0.13 & 0.008 & 0.003 & 0.02 & 0.019 & 0.005 & 0.00 \\
\hline $\mathrm{D} \cdot \ln \mathrm{L}$ & $\lambda_{d l}$ & -0.025 & 0.011 & 0.03 & -0.030 & 0.010 & 0.00 & 0.000 & 0.012 & 0.98 \\
\hline $\mathrm{D} \cdot \ln \mathrm{E}$ & $\lambda_{d e}$ & -0.001 & 0.001 & 0.10 & 0.001 & 0.001 & 0.26 & 0.001 & 0.001 & 0.42 \\
\hline $\mathrm{D} \cdot \ln \mathrm{M}$ & $\lambda_{d m}$ & 0.023 & 0.007 & 0.00 & 0.028 & 0.006 & 0.00 & 0.031 & 0.008 & 0.00 \\
\hline
\end{tabular}


Table 6. Parameter Estimates for Metalworking Machinery (SIC 354), continued.

\begin{tabular}{|c|c|c|c|c|c|c|c|c|c|c|}
\hline \multirow{2}{*}{$\begin{array}{l}\text { Year } \\
\text { Variable }\end{array}$} & \multirow[b]{2}{*}{ Param. } & \multicolumn{3}{|c|}{1992} & \multicolumn{3}{|c|}{1997} & \multicolumn{3}{|c|}{2002} \\
\hline & & Coeff. & Std. Err. & p Value & Coeff. & Std. Err. & Value & Coeff. & Std. Err. & p Value \\
\hline $\mathrm{LP} \cdot \ln \mathrm{K}$ & $\lambda_{l p k}$ & -0.0502 & 0.0680 & 0.46 & -0.0719 & 0.0762 & 0.35 & 0.0476 & 0.0610 & 0.44 \\
\hline $\mathrm{LP} \cdot \ln \mathrm{L}$ & $\lambda_{l p l}$ & 0.4071 & 0.2908 & 0.16 & 0.1668 & 0.2172 & 0.44 & 0.5938 & 0.1700 & 0.00 \\
\hline $\mathrm{LP} \cdot \ln \mathrm{E}$ & $\lambda_{\text {lpe }}$ & 0.0553 & 0.0233 & 0.02 & -0.0660 & 0.0193 & 0.00 & -0.0627 & 0.0128 & 0.00 \\
\hline $\mathrm{LP} \cdot \ln \mathrm{M}$ & $\lambda_{l p m}$ & -0.0204 & 0.1809 & 0.91 & 0.0397 & 0.1366 & 0.77 & 0.1275 & 0.1079 & 0.24 \\
\hline $\ln \mathrm{SP} \cdot \ln \mathrm{K}$ & $\lambda_{s p k}$ & 0.0031 & 0.0011 & 0.01 & 0.0006 & 0.0019 & 0.75 & -0.0008 & 0.0021 & 0.70 \\
\hline $\ln \mathrm{SP} \cdot \ln \mathrm{L}$ & $\lambda_{s p l}$ & 0.0082 & 0.0049 & 0.10 & 0.0044 & 0.0054 & 0.41 & -0.0149 & 0.0060 & 0.01 \\
\hline $\ln \mathrm{SP} \cdot \ln \mathrm{E}$ & $\lambda_{\text {spe }}$ & -0.0010 & 0.0004 & 0.01 & 0.0005 & 0.0005 & 0.35 & 0.0003 & 0.0005 & 0.52 \\
\hline $\ln \mathrm{SP} \cdot \ln \mathrm{M}$ & $\lambda_{s p m}$ & 0.0099 & 0.0030 & 0.00 & -0.0010 & 0.0034 & 0.77 & -0.0045 & 0.0038 & 0.24 \\
\hline $\ln \mathrm{SD} \cdot \ln \mathrm{K}$ & $\lambda_{s d k}$ & -0.0020 & 0.0008 & 0.01 & -0.0023 & 0.0015 & 0.12 & 0.0030 & 0.0017 & 0.08 \\
\hline $\ln \mathrm{SD} \cdot \ln \mathrm{L}$ & $\lambda_{s d l}$ & -0.0056 & 0.0033 & 0.08 & 0.0024 & 0.0042 & 0.57 & 0.0228 & 0.0048 & 0.00 \\
\hline $\ln \mathrm{SD} \cdot \ln \mathrm{E}$ & $\lambda_{s d e}$ & 0.0012 & 0.0003 & 0.00 & 0.0001 & 0.0004 & 0.82 & -0.0004 & 0.0004 & 0.30 \\
\hline $\ln \mathrm{SD} \cdot \ln \mathrm{M}$ & $\lambda_{s d m}$ & -0.0063 & 0.0020 & 0.00 & -0.0005 & 0.0027 & 0.85 & 0.0104 & 0.0030 & 0.00 \\
\hline $\ln \mathrm{RS} \cdot \ln \mathrm{K}$ & $\lambda_{r s k}$ & 0.0003 & 0.0006 & 0.64 & 0.0006 & 0.0009 & 0.53 & -0.0023 & 0.0012 & 0.05 \\
\hline $\ln \mathrm{RS} \cdot \ln \mathrm{L}$ & $\lambda_{r s l}$ & 0.0049 & 0.0027 & 0.08 & -0.0103 & 0.0025 & 0.00 & -0.0098 & 0.0032 & 0.00 \\
\hline $\ln \mathrm{RS} \cdot \ln \mathrm{E}$ & $\lambda_{r s e}$ & 0.0014 & 0.0002 & 0.00 & 0.0015 & 0.0002 & 0.00 & 0.0011 & 0.0002 & 0.00 \\
\hline $\ln \mathrm{RS} \cdot \ln \mathrm{M}$ & $\lambda_{r s m}$ & 0.0015 & 0.0017 & 0.38 & 0.0018 & 0.0016 & 0.27 & -0.0042 & 0.0021 & 0.05 \\
\hline $\ln \mathrm{PS} \cdot \ln \mathrm{K}$ & $\lambda_{p s k}$ & -0.0011 & 0.0012 & 0.35 & 0.0028 & 0.0014 & 0.05 & 0.0009 & 0.0018 & 0.60 \\
\hline $\ln \mathrm{PS} \cdot \ln \mathrm{L}$ & $\lambda_{p s l}$ & 0.0017 & 0.0051 & 0.74 & 0.0036 & 0.0040 & 0.38 & 0.0120 & 0.0049 & 0.01 \\
\hline $\ln \mathrm{PS} \cdot \ln \mathrm{E}$ & $\lambda_{p s e}$ & 0.0008 & 0.0004 & 0.05 & 0.0014 & 0.0004 & 0.00 & 0.0005 & 0.0004 & 0.16 \\
\hline $\ln \mathrm{PS} \cdot \ln \mathrm{M}$ & $\lambda_{p s m}$ & -0.0037 & 0.0032 & 0.25 & 0.0048 & 0.0026 & 0.06 & 0.0002 & 0.0031 & 0.96 \\
\hline $\mathrm{DE}$ & $v_{d e}$ & 79 & 0.0174 & 0.00 & 0.2099 & 0.0156 & .00 & 0.2165 & 0.0184 & 0.00 \\
\hline SE & $v_{s e}$ & -0.1732 & 0.0113 & 0.00 & -0.1249 & 0.0105 & 0.00 & -0.1583 & 0.0137 & 0.00 \\
\hline CR1 & $v_{c r l}$ & -0.0248 & 0.0222 & 0.26 & 0.0774 & 0.0228 & 0.00 & -0.0139 & 0.0276 & 0.61 \\
\hline CR2 & $v_{c r 2}$ & 0.0145 & 0.0158 & 0.36 & 0.0665 & 0.0193 & 0.00 & 0.0345 & 0.0200 & 0.09 \\
\hline CR3 & $v_{c r 3}$ & -0.0848 & 0.0250 & 0.00 & 0.0069 & 0.0227 & 0.76 & -0.0969 & 0.0307 & 0.00 \\
\hline $\ln \mathrm{PO}$ & $v_{p o p}$ & 0.0359 & 0.0093 & 0.00 & 0.0156 & 0.0084 & 0.06 & 0.0215 & 0.0121 & 0.08 \\
\hline UE & $v_{\text {ue }}$ & 0.5893 & 0.3471 & 0.09 & -0.1135 & 0.6295 & 0.86 & 2.1589 & 0.7531 & 0.00 \\
\hline ln INC & $v_{i n c}$ & -0.0238 & 0.0752 & 0.75 & -0.1051 & 0.0722 & 0.15 & -0.1869 & 0.0829 & 0.02 \\
\hline DV & $v_{d v}$ & -3.1462 & 1.3903 & 0.02 & -4.0410 & 1.3425 & 0.00 & -4.0307 & 1.2933 & 0.00 \\
\hline DH & $\rho_{d h}$ & -0.0179 & 0.0367 & 0.63 & -0.0143 & 0.0357 & 0.69 & 0.2221 & 0.0425 & 0.00 \\
\hline DVH & $\rho_{d v h}$ & 0.5574 & 1.0236 & 0.59 & -0.9196 & 0.7557 & 0.22 & -0.4974 & 1.0646 & 0.64 \\
\hline \multicolumn{4}{|c|}{ Generalized $\mathrm{R}^{2}$} & 0.999 & & & 0.999 & & & 0.999 \\
\hline \multicolumn{11}{|c|}{ Equation Adjusted $\mathrm{R}^{2}$} \\
\hline \multicolumn{4}{|c|}{ Production Function } & 0.942 & & & 0.952 & & & 0.935 \\
\hline \multicolumn{4}{|c|}{ Capital Cost Share } & 0.761 & & & 0.758 & & & 0.754 \\
\hline \multicolumn{4}{|c|}{ Labor Cost Share } & 0.745 & & & 0.739 & & & 0.737 \\
\hline \multicolumn{4}{|c|}{ Materials Cost Share } & 0.851 & & & 0.878 & & & 0.858 \\
\hline
\end{tabular}


Table 7. Parameter Estimates for Measuring and Controlling Devices (SIC 382).

\begin{tabular}{|c|c|c|c|c|c|c|c|c|c|c|}
\hline \multirow{3}{*}{$\begin{array}{l}\text { Year } \\
\text { Variable } \\
\text { constant }\end{array}$} & \multirow{3}{*}{$\begin{array}{l}\text { Param. } \\
\alpha_{0}\end{array}$} & \multicolumn{3}{|c|}{1992} & \multicolumn{3}{|c|}{1997} & \multicolumn{3}{|c|}{2002} \\
\hline & & Coeff. & Std. Err. & Value & Coeff. & td. Err. & Value & Coeff. & td. Err. & Value \\
\hline & & 8.279 & 0.027 & 0.00 & 8.491 & 0.027 & 0.00 & 8.773 & 0.048 & 0.00 \\
\hline $\ln \mathrm{K}$ & $\alpha_{k}$ & 0.094 & 0.001 & 0.00 & 0.122 & 0.002 & 0.00 & 0.128 & 0.002 & 0.00 \\
\hline $\ln \mathrm{L}$ & $\alpha_{l}$ & 0.431 & 0.005 & 0.00 & 0.398 & 0.005 & 0.00 & 0.396 & 0.006 & 0.00 \\
\hline $\ln \mathrm{E}$ & $\alpha_{e}$ & 0.011 & 0.000 & 0.00 & 0.009 & 0.000 & 0.00 & 0.008 & 0.000 & 0.00 \\
\hline $\ln M$ & $\alpha_{m}$ & 0.374 & 0.005 & 0.00 & 0.377 & 0.004 & 0.00 & 0.367 & 0.005 & 0.00 \\
\hline$(\ln K)^{2}$ & $\beta_{k k}$ & 0.072 & 0.001 & 0.00 & 0.073 & 0.001 & 0.00 & 0.065 & 0.002 & 0.00 \\
\hline$(\ln L)^{2}$ & $\beta_{l l}$ & 0.135 & 0.004 & 0.00 & 0.121 & 0.003 & 0.00 & 0.121 & 0.004 & 0.00 \\
\hline$(\ln E)^{2}$ & $\beta_{e e}$ & 0.008 & 0.000 & 0.00 & 0.009 & 0.000 & 0.00 & 0.006 & 0.000 & 0.00 \\
\hline$(\ln M)^{2}$ & $\beta_{m m}$ & 0.146 & 0.003 & 0.00 & 0.158 & 0.003 & 0.00 & 0.145 & 0.003 & 0.00 \\
\hline $\ln \mathrm{K} \cdot \ln \mathrm{L}$ & $\beta_{k l}$ & -0.036 & 0.001 & 0.00 & -0.026 & 0.001 & 0.00 & -0.026 & 0.002 & 0.00 \\
\hline $\ln \mathrm{K} \cdot \ln \mathrm{E}$ & $\beta_{k e}$ & 0.000 & 0.000 & 0.43 & -0.002 & 0.000 & 0.00 & -0.001 & 0.000 & 0.00 \\
\hline $\ln \mathrm{K} \cdot \ln \mathrm{M}$ & $\beta_{k m}$ & -0.040 & 0.001 & 0.00 & -0.048 & 0.001 & 0.00 & -0.043 & 0.001 & 0.00 \\
\hline $\ln \mathrm{L} \cdot \ln \mathrm{E}$ & $\beta_{l e}$ & -0.003 & 0.000 & 0.00 & -0.002 & 0.000 & 0.00 & -0.002 & 0.000 & 0.00 \\
\hline $\ln \mathrm{L} \cdot \ln \mathrm{M}$ & $\beta_{l m}$ & -0.108 & 0.003 & 0.00 & -0.107 & 0.002 & 0.00 & -0.105 & 0.003 & 0.00 \\
\hline $\ln \mathrm{E} \cdot \ln \mathrm{M}$ & $\beta_{\text {em }}$ & -0.005 & 0.000 & 0.00 & -0.005 & 0.000 & 0.00 & -0.004 & 0.000 & 0.00 \\
\hline D & $\gamma_{d}$ & -0.353 & 0.183 & 0.05 & -0.250 & 0.144 & 0.08 & 0.118 & 0.179 & 0.51 \\
\hline LP & $\gamma_{l p}$ & 1.326 & 0.843 & 0.12 & 0.365 & 0.615 & 0.55 & -0.268 & 0.889 & 0.76 \\
\hline $\ln \mathrm{SP}$ & $\gamma_{s p}$ & -0.022 & 0.026 & 0.40 & 0.028 & 0.019 & 0.13 & -0.004 & 0.022 & 0.87 \\
\hline $\ln \mathrm{SD}$ & $\gamma_{s d}$ & 0.003 & 0.023 & 0.90 & -0.017 & 0.018 & 0.34 & -0.017 & 0.024 & 0.48 \\
\hline $\ln \mathrm{RS}$ & $\gamma_{r s}$ & 0.024 & 0.012 & 0.04 & 0.017 & 0.010 & 0.09 & 0.011 & 0.013 & 0.40 \\
\hline $\ln \mathrm{PS}$ & $\gamma_{p s}$ & 0.091 & 0.044 & 0.04 & 0.082 & 0.039 & 0.04 & 0.061 & 0.042 & 0.15 \\
\hline $\mathrm{D}^{2}$ & $\delta_{d d}$ & 1.219 & 0.951 & 0.20 & 2.706 & 1.217 & 0.03 & -3.046 & 1.720 & 0.08 \\
\hline $\mathrm{D} \cdot \mathrm{LP}$ & $\delta_{d l p}$ & 7.862 & 4.016 & 0.05 & -3.220 & 3.825 & 0.40 & -6.706 & 5.826 & 0.25 \\
\hline $\mathrm{D} \cdot \ln \mathrm{SP}$ & $\delta_{d s p}$ & -0.109 & 0.140 & 0.44 & 0.115 & 0.118 & 0.33 & -0.372 & 0.182 & 0.04 \\
\hline $\mathrm{D} \cdot \ln \mathrm{SD}$ & $\delta_{d s d}$ & 0.071 & 0.107 & 0.51 & -0.173 & 0.109 & 0.11 & 0.157 & 0.132 & 0.24 \\
\hline $\mathrm{D} \cdot \ln \mathrm{RS}$ & $\delta_{d r s}$ & -0.013 & 0.053 & 0.81 & 0.058 & 0.062 & 0.36 & -0.139 & 0.076 & 0.07 \\
\hline $\mathrm{D} \cdot \ln \mathrm{PS}$ & $\delta_{d p s}$ & 0.025 & 0.275 & 0.93 & 0.118 & 0.262 & 0.65 & 0.626 & 0.305 & 0.04 \\
\hline $\mathrm{D} \cdot \ln \mathrm{K}$ & $\lambda_{d k}$ & 0.007 & 0.007 & 0.27 & -0.003 & 0.009 & 0.74 & -0.005 & 0.012 & 0.65 \\
\hline $\mathrm{D} \cdot \ln \mathrm{L}$ & $\lambda_{d l}$ & 0.064 & 0.022 & 0.00 & 0.035 & 0.021 & 0.10 & 0.024 & 0.027 & 0.39 \\
\hline $\mathrm{D} \cdot \ln \mathrm{E}$ & $\lambda_{d e}$ & -0.004 & 0.001 & 0.01 & -0.005 & 0.002 & 0.00 & -0.002 & 0.001 & 0.08 \\
\hline $\mathrm{D} \cdot \ln \mathrm{M}$ & $\lambda_{d m}$ & 0.036 & 0.018 & 0.04 & 0.024 & 0.019 & 0.22 & -0.004 & 0.024 & 0.88 \\
\hline
\end{tabular}


Table 7. Parameter Estimates for Measuring and Controlling Devices (SIC 382), continued.

\begin{tabular}{|c|c|c|c|c|c|c|c|c|c|c|}
\hline \multirow{2}{*}{$\begin{array}{l}\text { Year } \\
\text { Variable }\end{array}$} & \multirow[b]{2}{*}{ Param. } & \multicolumn{3}{|c|}{1992} & \multicolumn{3}{|c|}{1997} & \multicolumn{3}{|c|}{2002} \\
\hline & & Coeff. & Std. Err. & p Value & Coeff. & Std. Err. & Value & Coeff. & Std. Err. & p Value \\
\hline & $\lambda_{l p k}$ & -0.505 & 0.067 & 0.00 & -0.097 & 0.059 & 0.10 & 0.169 & 0.087 & 0.05 \\
\hline $\mathrm{LP} \cdot \ln \mathrm{L}$ & $\lambda_{l p l}$ & -1.369 & 0.212 & 0.00 & 0.010 & 0.149 & 0.95 & 0.334 & 0.199 & 0.09 \\
\hline $\mathrm{LP} \cdot \ln \mathrm{E}$ & $\lambda_{\text {lpe }}$ & -0.002 & 0.014 & 0.91 & -0.011 & 0.013 & 0.38 & -0.025 & 0.009 & 0.01 \\
\hline $\mathrm{LP} \cdot \ln \mathrm{M}$ & $\lambda_{l p m}$ & -1.371 & 0.180 & 0.00 & -0.417 & 0.134 & 0.00 & -0.044 & 0.176 & 0.80 \\
\hline $\ln \mathrm{SP} \cdot \ln \mathrm{K}$ & $\lambda_{s p k}$ & 0.010 & 0.002 & 0.00 & 0.003 & 0.002 & 0.10 & 0.003 & 0.002 & 0.20 \\
\hline $\ln \mathrm{SP} \cdot \ln \mathrm{L}$ & $\lambda_{s p l}$ & 0.028 & 0.006 & 0.00 & 0.004 & 0.005 & 0.33 & 0.004 & 0.006 & 0.49 \\
\hline $\ln \mathrm{SP} \cdot \ln \mathrm{E}$ & $\lambda_{\text {spe }}$ & 0.001 & 0.000 & 0.00 & 0.000 & 0.000 & 0.70 & 0.001 & 0.000 & 0.00 \\
\hline $\ln \mathrm{SP} \cdot \ln \mathrm{M}$ & $\lambda_{s p m}$ & 0.030 & 0.005 & 0.00 & 0.006 & 0.004 & 0.17 & 0.010 & 0.005 & 0.05 \\
\hline $\ln \mathrm{SD} \cdot \ln \mathrm{K}$ & $\lambda_{s d k}$ & -0.005 & 0.002 & 0.00 & -0.003 & 0.002 & 0.11 & -0.004 & 0.002 & 0.08 \\
\hline $\ln \mathrm{SD} \cdot \ln \mathrm{L}$ & $\lambda_{s d l}$ & -0.016 & 0.005 & 0.00 & -0.001 & 0.004 & 0.89 & -0.001 & 0.006 & 0.82 \\
\hline $\ln \mathrm{SD} \cdot \ln \mathrm{E}$ & $\lambda_{s d e}$ & -0.001 & 0.000 & 0.07 & 0.000 & 0.000 & 0.82 & -0.001 & 0.000 & 0.00 \\
\hline $\ln \mathrm{SD} \cdot \ln \mathrm{M}$ & $\lambda_{s d m}$ & -0.019 & 0.005 & 0.00 & -0.005 & 0.004 & 0.23 & -0.014 & 0.005 & 0.01 \\
\hline $\ln \mathrm{RS} \cdot \ln \mathrm{K}$ & $\lambda_{r s k}$ & -0.001 & 0.001 & 0.54 & -0.001 & 0.001 & 0.17 & 0.001 & 0.001 & 0.48 \\
\hline $\ln \mathrm{RS} \cdot \ln \mathrm{L}$ & $\lambda_{r s l}$ & 0.013 & 0.003 & 0.00 & 0.009 & 0.003 & 0.00 & 0.005 & 0.003 & 0.12 \\
\hline $\ln \mathrm{RS} \cdot \ln \mathrm{E}$ & $\lambda_{\text {rse }}$ & 0.000 & 0.000 & 0.36 & 0.000 & 0.000 & 0.40 & 0.000 & 0.000 & 0.00 \\
\hline $\ln \mathrm{RS} \cdot \ln \mathrm{M}$ & $\lambda_{r s m}$ & 0.003 & 0.003 & 0.23 & -0.002 & 0.002 & 0.37 & 0.001 & 0.003 & 0.71 \\
\hline $\ln \mathrm{PS} \cdot \ln \mathrm{K}$ & $\lambda_{p s k}$ & 0.000 & 0.003 & 0.96 & -0.001 & 0.003 & 0.79 & 0.004 & 0.004 & 0.29 \\
\hline $\ln \mathrm{PS} \cdot \ln \mathrm{L}$ & $\lambda_{p s l}$ & 0.027 & 0.011 & 0.01 & 0.017 & 0.008 & 0.05 & 0.028 & 0.009 & 0.00 \\
\hline $\ln \mathrm{PS} \cdot \ln \mathrm{E}$ & $\lambda_{p s e}$ & -0.001 & 0.001 & 0.22 & 0.001 & 0.001 & 0.07 & 0.000 & 0.000 & 0.27 \\
\hline $\ln \mathrm{PS} \cdot \ln \mathrm{M}$ & $\lambda_{p s m}$ & -0.003 & 0.009 & 0.72 & 0.002 & 0.007 & 0.76 & -0.002 & 0.008 & 0.78 \\
\hline $\mathrm{DE}$ & $v_{d e}$ & 0.231 & 0.035 & 0.00 & 0.251 & 0.032 & 0.00 & 0.275 & 0.036 & 0.00 \\
\hline SE & $v_{s e}$ & -0.272 & 0.029 & 0.00 & -0.254 & 0.026 & 0.00 & -0.222 & 0.031 & 0.00 \\
\hline CR1 & $v_{c r l}$ & 0.019 & 0.037 & 0.61 & -0.008 & 0.032 & 0.81 & -0.089 & 0.051 & 0.08 \\
\hline CR2 & $v_{c r 2}$ & -0.007 & 0.039 & 0.87 & -0.024 & 0.039 & 0.54 & -0.117 & 0.043 & 0.01 \\
\hline CR3 & $v_{c r 3}$ & 0.015 & 0.033 & 0.65 & 0.077 & 0.031 & 0.01 & -0.080 & 0.053 & 0.13 \\
\hline ln POP & $v_{p o p}$ & -0.013 & 0.032 & 0.68 & 0.049 & 0.021 & 0.02 & 0.076 & 0.027 & 0.00 \\
\hline $\mathrm{UE}$ & $v_{u e}$ & -0.807 & 1.320 & 0.54 & -2.820 & 1.348 & 0.04 & 1.527 & 2.072 & 0.46 \\
\hline $\ln$ INC & $v_{i n c}$ & -0.307 & 0.136 & 0.02 & -0.091 & 0.129 & 0.48 & -0.092 & 0.158 & 0.56 \\
\hline DV & $v_{d v}$ & -22.144 & 7.819 & 0.00 & -9.545 & 5.659 & 0.09 & -5.854 & 8.807 & 0.51 \\
\hline DH & $\rho_{d h}$ & -0.064 & 0.110 & 0.56 & 0.111 & 0.086 & 0.20 & 0.028 & 0.103 & 0.78 \\
\hline DVH & $\rho_{d v h}$ & 1.110 & 6.508 & 0.86 & 3.980 & 3.760 & 0.29 & -4.138 & 6.506 & 0.52 \\
\hline \multicolumn{4}{|c|}{ Generalized $\mathrm{R}^{2}$} & 0.998 & & & 0.998 & & & 0.998 \\
\hline \multicolumn{11}{|c|}{ Equation Adjusted $\mathrm{R}^{2}$} \\
\hline \multicolumn{4}{|c|}{ Production Function } & 0.941 & & & 0.946 & & & 0.937 \\
\hline \multicolumn{4}{|c|}{ Capital Cost Share } & 0.746 & & & 0.763 & & & 0.676 \\
\hline \multicolumn{4}{|c|}{ Labor Cost Share } & 0.655 & & & 0.646 & & & 0.621 \\
\hline \multicolumn{4}{|c|}{ Materials Cost Share } & 0.803 & & & 0.837 & & & 0.790 \\
\hline
\end{tabular}


plastics models show mixed results. The difference across the study industries is consistent with an industry lifecycle interpretation: technology- and innovation-intensive industries benefit from diversity of thought and spillovers across industries, whereas traditional manufacturing profits from local resources being targeted specifically toward a restricted set of regional strengths. Despite the sizeable coefficients, the influence of industrial diversity is small: a standard deviation increase in industrial diversity from the sample mean is associated with a climb in output of about four percent in the model with the largest coefficient. ${ }^{16}$ The effects of the change in diversity from the historic period to the sample year are negligible.

The three Census region dummies evidence a surprising degree of variation over time within industries. This may indicate that the dummies are capturing macro-regional differences in economic conditions not apparent in examining the three industries at the national scale. Shifts in military contracting patterns also may play a role.

Agglomeration Economies. As noted earlier, labor pooling advantages might be expected to be the least important to plants in the rubber and plastics industry, judging from the industries' relative reliance on labor inputs. In fact, the benefits of potential regional labor pools are not very large and vary by year for each industry. For measuring and controlling devices in the 1992 model, a two percent rise in the distance-weighted fraction of the local workforce employed in the top 15 occupations is associated with a 2.7 percent increase in output. ${ }^{17}$ That figure drops to less than one percent in 1997 and becomes negative in 2002. For metalworking machinery, two of the sample years show negative productivity impacts. Rubber and plastics plants benefit from labor pooling potential in 1992 and 2002, but in 1997 the effect is negligible. Labor pooling is the only agglomeration economy measured on a relative rather than an absolute scale; its influence may be captured to some degree by the size-sensitive agglomeration variables and population density.

Supply pooling demonstrates few discernible and unambiguous impacts on production. The estimated coefficients are rarely large enough to be important, and in most of the models, the coefficients of the two supply pooling variables are of opposite sign. Since the two variables are

\footnotetext{
${ }^{16}$ The Herfindahl-Hirschman index of industrial diversity has quite small mean values and standard deviations across the nine samples (Table 3).

${ }^{17}$ Labor pooling is constructed as a ratio and enters the production function directly, without a logarithmic transformation. The coefficient is interpreted as the percent change in output associated with a 100 percent rise from the sample mean in the distance-weighted fraction of the regional workforce employed in the top 15 occupations employed by that industry nationally. Two percent is roughly one standard deviation (see Table 3 ). The other four agglomeration economies enter in logarithmic form so their coefficients are elasticities.
} 
highly positively correlated (see Table 4), the likely conclusion is that the colinearity between these two variables obscures the individual effects on production. ${ }^{18}$

Stronger results are obtained for the two knowledge spillover variables. Rubber and plastics plants located in regions with greater private sector innovative activity as indicated by local patenting are more productive than plants sited in less innovative regions. The effects are large enough to be substantively important. In 1997 and 2002, a doubling of the regional patent rate in relevant technology fields is associated with a two percent higher output. The estimated coefficient in 1992 is approximately one eighth as large. It may be an aberration, an artifact of changing assignment propensities for patent technology classifications, or may indicate that the industry has only begun to benefit substantially from private sector innovation in the last fifteen years or so. The estimated effects are larger for the other two study industries. In 1992, the productivity gain to metalworking machinery establishments from doubling regional patenting is just shy of eight percent; in 2002 the figure is over ten percent. The corresponding impact in the measuring and controlling devices industry has trended downward, from nine percent in 1992 to six percent in 2002. Even considering the smallest of these estimates, the influence of regional private sector innovation is strong enough to suggest a possible route for local or regional policy measures to influence productivity.

Location proximate to academic research expenditures in fields germane to the industry has a much smaller impact on production than the regional patenting rate. In the metalworking machinery models, local academic research is actually a negative factor, perhaps obscured by the relatively high correlation between the academic research and manufactured input supply pooling variables. Only for measuring and controlling devices plants does academic research yield a notable productivity improvement: doubling the index of nearby academic research raises output by one to two percent depending on the sample year. Higher technology industries, in this study represented by the measuring and controlling devices sector, may have more to gain from localized knowledge spillovers of basic research. It is also possible that the academic research indicator acts in part as a proxy for higher local land or employment costs, a factor that varies less across the samples of measuring and controlling device manufacturing establishments

\footnotetext{
${ }^{18}$ Neither several alternative formulae for these two variables nor the replacement of both measures with a single encompassing supply pool variable succeeded in improving the model results.
} 
that are located primarily in dense and urban counties. ${ }^{19}$ The relatively small influence of academic research recorded in these models is not entirely unexpected, as the impacts of basic research are realized largely in the very long term and the variable tracks only one of the many means by which universities influence regional economic performance.

Regional Industrial Dominance. Regional industrial dominance is an influential negative factor in determining establishment-level productivity. In the metalworking machinery manufacturing industry, a rise of 20 percent in the total industry shipment value accounted for by the top five firms in an LMA is associated with a two percent decline in output at the sample means in 1992, and four percent in 1997 and 2002. ${ }^{20}$ The impact is greater for measuring and controlling device manufacturers: a 20 percent hike in the concentration ratio yields a seven percent drop-off in production in 1992 and a five percent drop in 1997. The estimated coefficient of dominance is positive but not significant in 2002. The rubber and plastics industry evidences smaller but still substantial effects from regional industrial dominance: declines of about 1 to 1.3 percent in output are associated with a 20 percent climb in the concentration ratio. These observations provide an answer to the first research question driving this study: all else being equal, manufacturing plants are less productive in regions in which the industry is locally dominated.

Because the production function includes dummy variables for relatively large and small firms in a regional industry, the coefficients of the regional industrial dominance measure do not simply reflect dominators outperforming locally dominated enterprises. Regional industrial dominance influences the production of a plant independently of its status as part of a dominator or a dominated firm. ${ }^{21}$ In all nine samples, dominator establishments outperform and dominated plants underperform the sample averages. The margins are substantial: dominators enjoy a 14 to 28 percent productivity advantage depending on the industry and year; dominated plants suffer a production deficit of similar magnitude. In each model, whether a plant belongs to a dominator

\footnotetext{
${ }^{19}$ In other words, the result may reflect higher production costs for rubber and plastics and for metalworking machinery plants in university towns versus non-urban regions without a major university presence.

${ }^{20}$ Like labor pooling, the dominance variable is a ratio by construction and is not logarithmically transformed to enter the production function. Its coefficient is interpreted as the percent change in output associated with a rise in the concentration ratio of 100 percent from the sample mean. The figure of 20 percent represents approximately one standard deviation of the concentration ratio dominance measure in the estimation samples (see Table 3).

${ }^{21}$ Interactions between dominance and the dominance classification dummies tested in alternate specifications are inconsistent and insignificant. Either regional industrial dominance affects plants of all types equally or, more likely, the regression does not possess sufficient statistical power to distinguish among dominance productivity effects according to establishment dominance status.
} 
firm, a dominated firm, or neither is the strongest single influence on output other than input quantities. These impacts—-both the direction and the scale—are to be expected. Dominator firms have more resources at their disposal and generally can take advantage of economies of scale, whereas dominated firms have access to fewer resources and economies of scale than the average industry establishment. In the cross-sectional modeling context, the causal direction of the effects indicated by the dummy variables is ambiguous; dominant firms may have achieved their relative size due to unobserved firm-specific efficiencies.

The influence of dominance on establishment productivity appears to be primarily a current phenomenon. The estimated coefficients of the historic dominance term are mostly insignificant and small in comparison to the typical twenty-year change in the concentration ratio measure of dominance. ${ }^{22}$ Omitting the historic dominance variable entirely leaves the current dominance coefficients about the same. The minimal influence of historic dominance is reasonable given the changes in industry composition, products and production technologies, and national economic conditions over the intervening period.

The figures in the preceding paragraphs are direct effects, equal to the marginal effects of dominance evaluated at the sample means of all of the independent variables. Regional industrial dominance, however, enters the production function nonlinearly, with a quadratic term and interactions with both the standard input and agglomeration economy variables. Therefore the estimated marginal effects of dominance vary with the levels of inputs and potential agglomeration economies and also with the base level of dominance. The nonlinearities modeled in this way are simple, just an increasing or decreasing trend in relation to the interacted variable (Aiken and West 1991). ${ }^{23}$ For instance, in the rubber and plastics industry, and for the measuring and controlling devices industry in 2002, the coefficient of the square of dominance is large and negative, so that the negative impact of dominance on performance increases as the level of dominance rises. The opposite holds in 1992 and 1997 for the metalworking machinery and the measuring and controlling devices industries: the positive dominance-squared term

\footnotetext{
${ }^{22}$ Note that Table 3 does not display the change in dominance, but rather the level of dominance twenty years prior.

${ }^{23}$ Given the number of variables included in this translog production function model, more complex specifications would quickly surpass the statistical power of the estimation procedure. Although it is possible to calculate the marginal effect of dominance at any point within or even external to the sample set, the sheer volume of possibilities makes such an exploration intractable.
} 
indicates that the deleterious effects of dominance on production are felt most acutely in those regions with moderate levels of industrial dominance. ${ }^{24}$

The ways in which the influence of dominance on establishment-level productivity change with alterations in the levels of standard inputs and agglomeration economies are relevant for policymaking, since agglomeration potential varies widely across regions and the quantities of standard production inputs are a useful proxy for establishment size. This portion of the analysis contrasts regions with less than average potential agglomeration economies with better endowed LMAs, and considers the range of plant sizes as indicated by the volume of inputs. It is worth reiterating that the point of estimation is at the sample means, and the estimations are less reliable moving further away from the means. ${ }^{25}$ The variation in the effects of regional industrial dominance is interpreted qualitatively, emphasizing broad trends rather than specific results.

Figure 1 displays the estimated marginal impacts of regional industrial dominance on output and their 90 percent confidence intervals for different points in the range of standard input quantities. ${ }^{26}$ In the rubber and plastics industry, the effects of regional industrial dominance in are small but negative at the sample means. In 1997, as plant size shifts away from the mean amounts of the four standard inputs, the effect of dominance changes only slightly while the significance of the estimate declines (the confidence intervals widen and include zero). In 1992 and 2002, however, small plants experience greater and more significantly negative effects of dominance. In other words, dominance acts as more of a hindrance to productivity performance

\footnotetext{
${ }^{24}$ At low levels of dominance, the impact on production is small because there is very little dominance. At high levels of dominance, the negative contribution to production represented by the linear dominance term is balanced by the positive quadratic term.

${ }^{25}$ This is reflected in part by the increasing width of the confidence intervals moving away from the means in Figures 1 and 2.

${ }^{26}$ The graphs' vertical axes represent the estimated marginal impact of dominance, interpreted in the same way as the estimated coefficients of dominance reported in Tables 5 through 7: the percent change in output associated with a 100 rise in the concentration ratio from the sample mean, with all other variables held constant. The horizontal axes provide six points that describe the range from low to high quantities of the four standard inputs. The point labeled "mean" is defined by the sample mean values for the four standard inputs: capital, labor, energy, and materials. The disclosure restrictions that protect the confidentiality of data pertaining to individual establishments preclude the use of percentiles to populate the rest of the input range; using hypothetical combinations of inputs rather than actual sample observations is a device that upholds confidentiality requirements. Therefore, the five points labeled "A" through "E" are constructed as percentages of the sample means. A, B, and C are smaller than the mean and $\mathrm{D}$ and $\mathrm{E}$ are larger than the mean. At each of these points, the sample means for capital, labor, energy, and materials are multiplied by selected fractions and the estimated marginal impact of regional dominance is calculated for the resulting input quantities. The five fractions for points A through $\mathrm{E}$ are chosen separately for each of the four inputs in each of the nine samples to approximate the range observed in that sample. The horizontal axes are not to scale; the six points are not equally spaced along the continuum from low to high input quantities.
} 
for the lower throughput, smaller rubber and plastics plants in 1992 and in 2002. The largest establishments even benefit from industrial dominance in their regions. The latter pattern is replicated in most of the graphs in Figure 1: the marginal effect of dominance is greater in magnitude (a larger negative number) and more significant for smaller plants. Only the 1992 metalworking machinery (SIC 354) and the 2002 measuring and controlling devices (SIC 382) models display a result more like 1997 rubber and plastics, wherein the effect of dominance is relatively stable across establishment sizes. Industry-specific conditions in those particular years may have favored the smaller firms in dominated regional industries.

The estimated impacts of regional industrial dominance vary less with the agglomeration regime than they do with input quantities (Figure 2). ${ }^{27}$ In two of the models, rubber and plastics and measuring and controlling devices in 2002, dominance has positive productivity effects in regions with few available agglomeration economies and negative effects where the levels of agglomeration economies are large. Dominance may hinder local establishments from accessing agglomeration economies, thus lowering productivity below expectations primarily in regions offering greater potential agglomeration benefits. Locally dominant firms in areas that lack agglomeration economies may create alternative advantages through local economic power (such as specialized training programs or applied research institutes) that then spill over to smaller firms in the regional industry.

Most of the remaining models, however, demonstrate little change in dominance with different levels of agglomeration economies. Together with the observations in the previous section pertaining to the direct impacts of agglomeration economies, this yields an answer to the second research question. For the majority of study industries and years, it does not seem to be the case that small establishments in regionally dominated industries are less productive because they cannot realize benefits from potential localized agglomeration economies. It is possible that the samples are too small, the translog model too complex, or the sought-after effects too subtle to be perceptible in the model results. The variables may indicate the wrong sources of agglomeration economies (for example, capital or financing availability is not tracked). The most direct conclusion, however, is that though dominance reduces establishment-level

\footnotetext{
${ }^{27}$ Figure 2 is constructed in the same way as Figure 1 but with points that vary across the observed range of the agglomeration economy variables rather than the production inputs for each industry-year sample. As with the graphs in 1, the points on the horizontal axes do not represent actual combinations of the agglomeration economies present in particular LMAs, but rather hypothetical regional endowments that approximate the spectrum from minimal to maximal available agglomeration economies.
} 
Figure 1. Marginal Impacts of Regional Industrial Dominance Across Range of Standard Inputs.
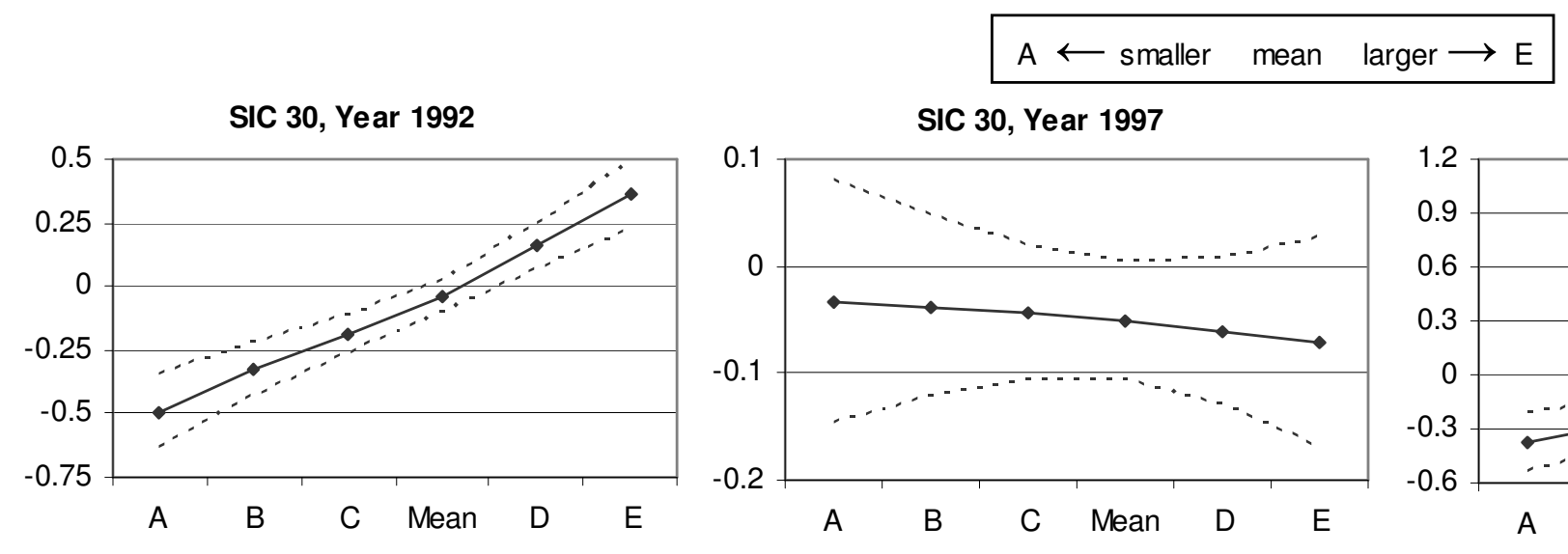

-.... Estimate SIC 30, Year 2002
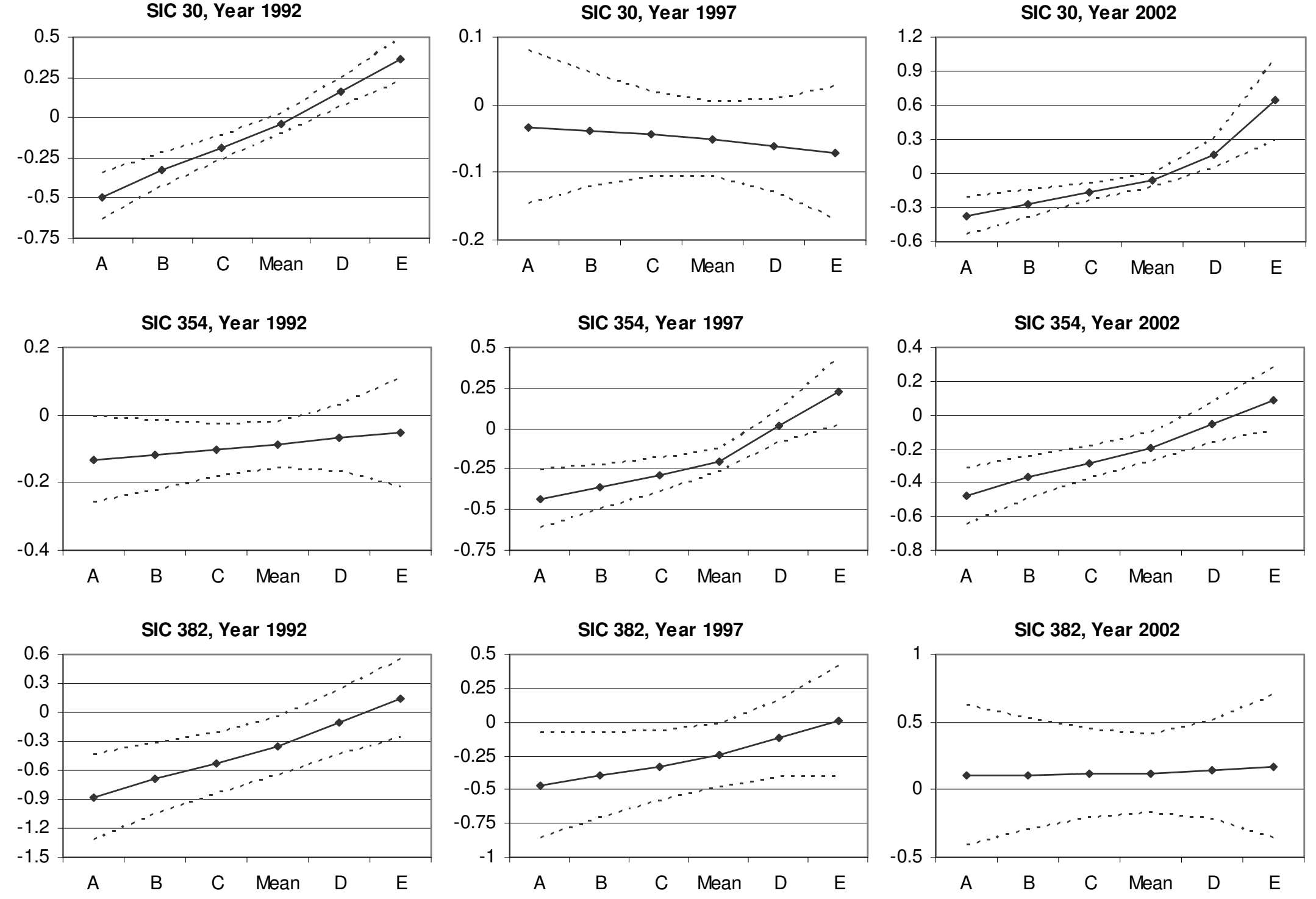
Figure 2. Marginal Impacts of Regional Industrial Dominance Across Range of Agglomeration Economies.
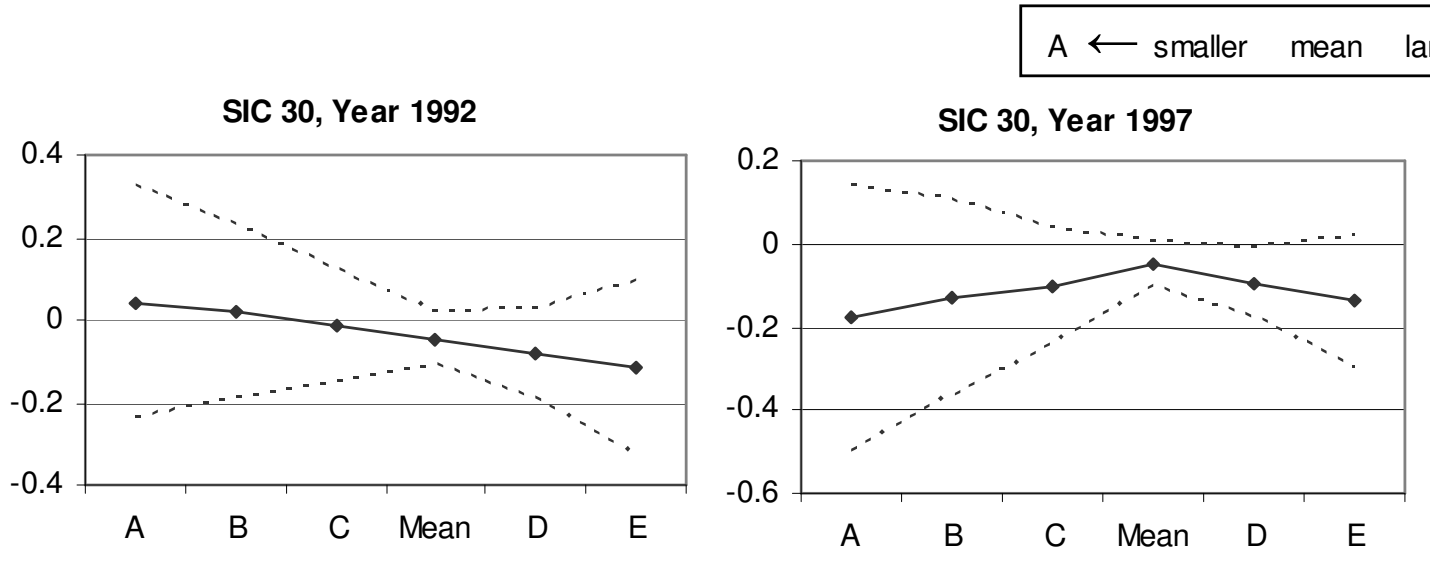

larger $\rightarrow E$

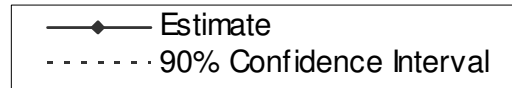

\section{SIC 30, Year 2002}

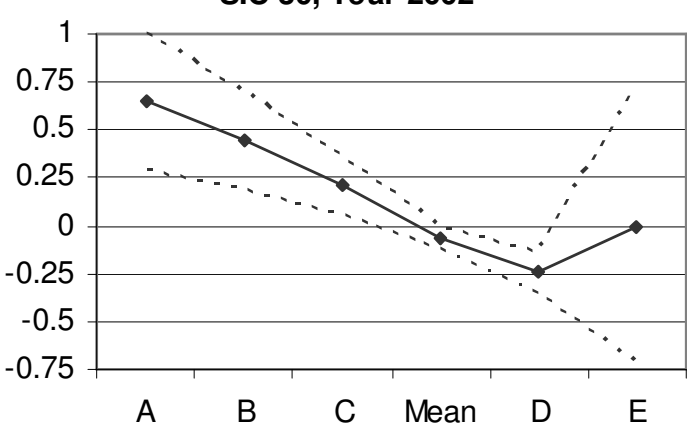

SIC 354, Year 1992
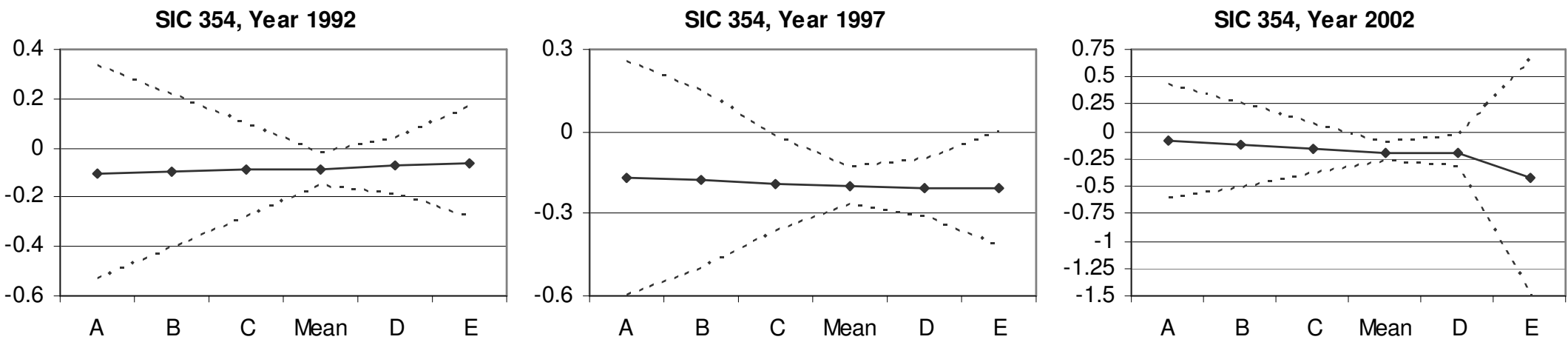

SIC 382, Year 1992
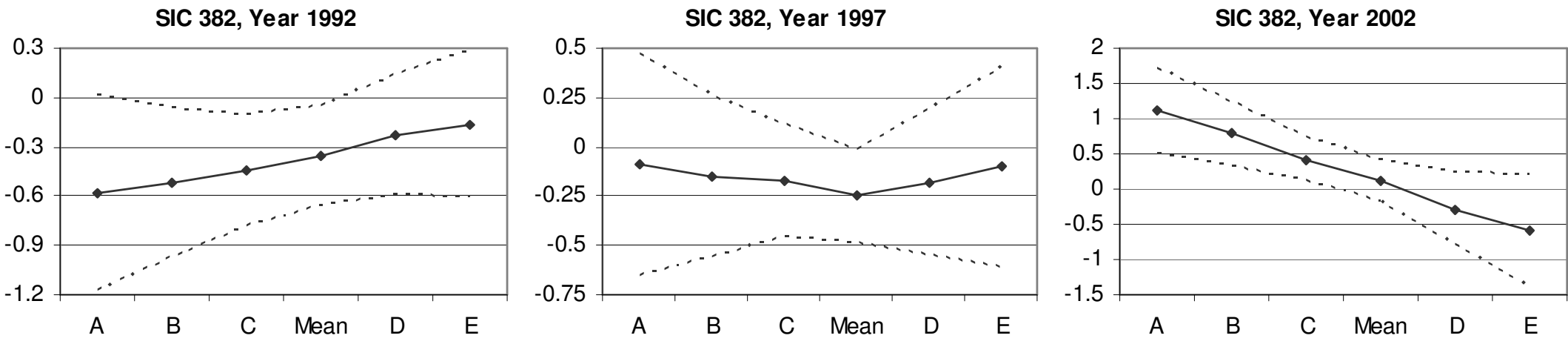
productivity, the mechanism by which that outcome is realized is not the restriction of the ability of regional manufacturers to access local benefits of agglomeration.

\section{SUMMARY AND CONCLUSIONS}

This paper estimates a translog production function system for nine cross-sectional establishment-level samples representing three years and three contrasting manufacturing industries. We include measures of regional industrial dominance and sources of agglomeration economies in the estimation system to investigate two primary research questions: does regional industrial dominance lead to lower productivity for manufacturing plants, and can any such lower productivity be traced to limits in establishments' capacity to capture agglomeration economies?

The evidence strongly suggests that regional industrial dominance does reduce manufacturing productivity. Plants located in regions in which their industries are dominated are substantially less productive than establishments in the same industries that are located in other areas. Relatively small plants are especially vulnerable. The extent to which regional industrial dominance hampers production is greatest in the measuring and controlling devices industry and smallest for rubber and plastics establishments, suggesting that dominance may be more of a factor in technology-intensive sectors.

The results largely falsify the second research hypothesis. The potential labor and supply pooling agglomeration variables display weak and inconsistent effects on output. Although the two knowledge spillover variables have beneficial impacts on productivity that are stronger in the more technology-intensive measuring and controlling device industry, in only two of the nine samples is there evidence of the anticipated relationship of regional industrial dominance lowering productivity in regions offering greater potential agglomeration economies. For the majority of the industry-year pairs, there is little interaction between dominance and agglomeration. Still, the second research hypothesis cannot be conclusively rejected. The direct impacts of the three labor and supply pooling agglomeration variables are themselves small and inconsistent. Either the data or the methodology is inadequate for detecting the connection, or dominance does not typically reduce productivity via preventing manufacturers from taking advantage of regional agglomeration economies. 
This analysis highlights the importance of regional industrial structures and also raises additional questions for economic development practitioners and policymakers. The primary conclusion is that regional industrial dominance restrains the productivity of manufacturing plants. Locally dominated firms are particularly vulnerable and may require extra attention and support. The results regarding the second research question underscore the challenge of devising economic development policy. Dominance is a phenomenon that by its nature is likely to endure over time and is difficult to alter directly with the policy tools available at the local and regional levels. Intervening to shape the sources of agglomeration economies does not appear to be the route toward influencing the role of dominance and without additional knowledge it is difficult to devise alternative programs intended to help small businesses counter the negative effects of a non-competitive regional corporate structure. More research on the specific linkage between dominance and economic performance is therefore needed.

Lastly, the estimates pertaining to the agglomeration economy measures provide information directly useful to economic development policymakers. Locational factors that affect economic performance are more susceptible to policy influence than are firm-specific traits (Hoogstra and van Dijk 2004). Knowledge and information spillovers from private sector innovative activity benefit production. Proximity to academic research in relevant fields improves the productivity of measuring and controlling device establishments, and may have a similar influence for other technology-intensive industries. It may be more effective to support private and public research efforts than to attempt to establish or mediate local supplierpurchaser relationships. 


\section{APPENDICES}

Appendix A: Derivation of Cost Share Equations

Following Kim (1992) and Feser (2002), a set of cost share equations are derived from the standard first order conditions representing profit maximization. Let the production function be expressed generally as:

$$
Q=g(Z) \cdot f(X)
$$

where $Q$ is firm output, $X$ is a vector of conventional inputs, and $Z$ is a vector of other relevant regional characteristics. The firm seeks to maximize the profit function

$$
\Pi=\frac{\partial C}{\partial Q} Q-\sum_{i} P_{i} X_{i}
$$

where $\Pi$ is total profits, $\partial C / \partial Q$ is the marginal cost of output, and $P_{i}$ is the input price of the $\mathrm{i}^{\text {th }}$ input $X_{i}$. Given that the production function satisfies the typical regularity conditions and that input markets are competitive, the first-order condition for profit maximization is:

$$
\frac{\partial \Pi}{\partial X_{i}}=\frac{\partial C}{\partial Q} \cdot \frac{\partial Q}{\partial X_{i}}-P_{i}=0
$$

for each input $X_{i}$, and, rearranging,

$$
\frac{\partial Q}{\partial X_{i}}=\frac{P_{i}}{\partial C / \partial Q}=\lambda P_{i}
$$

where $\lambda$ is a Lagrange multiplier, the reciprocal of the marginal cost of output. (A4) holds for each input, so both sides may be multiplied by the $\mathrm{i}^{\text {th }}$ input quantity, $X_{i}$, and summed to yield a multiple of the total input cost $C$ :

$$
\sum_{i} \frac{\partial Q}{\partial X_{i}} X_{i}=\lambda \sum_{i} X_{i} P_{i}=\lambda C
$$

The inverse demand function is obtained by rearranging (A5) and substituting into (A4):

$$
P_{i}=C \frac{\partial Q / \partial X_{i}}{\sum_{i}\left(\partial Q / \partial X_{i}\right) X_{i}}
$$

Rewriting (A6) in terms of logarithmic input and outputs gives:

$$
P_{i}=C \frac{\left(\partial \ln Q / \partial \ln X_{i}\right)\left(Q / X_{i}\right)}{\sum_{i}\left(\partial \ln Q / \partial \ln X_{i}\right)\left(Q / X_{i}\right) X_{i}}=C \frac{\partial \ln Q / \partial \ln X_{i}}{\sum_{i}\left(\partial \ln Q / \partial \ln X_{i}\right) X_{i}} .
$$

Rearranging again yields an equation for the cost share, $S_{i}$, for the $\mathrm{i}^{\text {th }}$ input: 


$$
S_{i} \equiv \frac{P_{i} X_{i}}{C}=\frac{\partial \ln Q / \partial \ln X_{i}}{\sum_{i}\left(\partial \ln Q / \partial \ln X_{i}\right)} .
$$

The logarithmic marginal products of each input are obtained by differentiating the production function in equation (1) in the main text with respect to $X_{i}$ :

$$
\begin{aligned}
\frac{\partial \ln Q}{\partial \ln X_{i}} & =\alpha_{i}+\frac{1}{2} \sum_{j} \beta_{i j} \ln X_{j}+\frac{1}{2} \sum_{j} \beta_{j i} \ln X_{j}+\sum_{k} \mathrm{I}(i, k) \lambda_{i k} \ln Z_{k} \\
& =\alpha_{i}+\sum_{j} \beta_{i j} \ln X_{j}+\sum_{k} \mathrm{I}(i, k) \lambda_{i k} \ln Z_{k}
\end{aligned} .
$$

Substituting (A9) into (A8), the cost shares, $S_{i}$, for the translog production function are:

$$
S_{i}=\frac{\partial \ln Q / \partial \ln X_{i}}{\sum_{i}\left(\partial \ln Q / \partial \ln X_{i}\right)}=\frac{\alpha_{i}+\sum_{j} \beta_{i j}\left(\ln X_{j}\right)+\sum_{k} I(i, k) \lambda_{i k} \ln Z_{k}}{\sum_{i}\left(\alpha_{i}+\sum_{j} \beta_{i j}\left(\ln X_{j}\right)+\sum_{k} I(i, k) \lambda_{i k} \ln Z_{k}\right)} .
$$

The only assumptions required for this derivation are the production function regularity conditions, firm-level profit maximization, and competitive input markets.

\section{Appendix B: Details of Variable Construction and Data Sources}

Input and Output Variables. All monetary values are in units of thousands of nominal dollars and all time measures are in units of thousands of hours.

Output $(Q)$ is the total value of shipments adjusted for inventories and work in progress:

$$
Q=T V S+(W I E-W I B)+(F I E-F I B) .
$$

TVS is the total value of shipments, WIE and WIB are work in progress at the end and beginning of the year, and FIE and FIB are end-of-year and beginning-of-year finished product inventories.

Establishment-level measures of capital are often constructed with perpetual inventory methods, requiring multiple observations on the same plant over time. For this study, such a measure would disallow most small establishments from the samples and make it impossible to examine the effects of regional industrial dominance effectively. Instead, a measure for capital based on gross stocks is used. Measures of capital based on current assets have been shown to perform well in micro-level research using the LRD (Doms 1996; Dwyer 1997; Syverson et al. 2005). Capital $(K)$ is the sum of total end-of-year capital assets, capitalized building rental expenditures, and capitalized machinery rental expenditures: 


$$
K=T A E+\frac{B R}{B P R}+\frac{M R}{M P R} .
$$

$T A E$ is total end-of-year building and machinery assets, $B R$ is building rental expenditures, $M R$ is machinery rental expenditures, and $B P R$ and $M P R$ are constructed by averaging national annual industry-specific (3-digit SIC) capital asset price (unpublished) estimates obtained from the Bureau of Labor Statistics across asset categories.

Labor $(L)$ is production-worker-equivalent hours, calculated by adding production worker and other worker wages and dividing by the ratio of production worker wages to hours:

$$
L=\frac{W P+W N P}{(W P / P H)}
$$

$W P$ is production worker payroll, WNP is non-production worker payroll, and $P H$ is production worker hours. $^{28}$

Energy $(E)$ is the amount of purchased electricity plus the estimated quantity of purchased fuels:

$$
E=C F\left(\frac{1,000}{E P R}\right)+P E\left(\frac{3,412.705}{1,000}\right) .
$$

$P E$ is the quantity of purchased electricity in millions of British Thermal Units, $C F$ is the cost of purchased fuels, and EPR is the average state-level energy price for the industrial sector reported in the State Energy Data System of the U.S. Energy Information Administration. ${ }^{29}$

Materials $(M)$ is the total cost of materials, parts, contract work, resales, purchased services, and repairs, adjusted for changes in materials inventories:

$$
M=C P+C R+C W+C P C+R B+R M+(M I B-M I E) .
$$

$C P$ is cost of materials and parts, $C R$ is expenditures for resales, $C W$ is the cost of contract work, $C P C$ is purchased communications services, $R B$ and $R M$ are building and machinery repairs, and $M I B-M I E$ is the difference between materials inventories at the beginning and end of the year.

Capital costs are the sum of total capital assets adjusted by multiplying by (unpublished) Bureau of Labor Statistics capital asset prices and building and machinery rental costs taken

\footnotetext{
${ }^{28}$ For the very small number of observations with positive reported production worker wages but no reported production worker hours, the average ratio of production worker wages to production worker hours for all establishments in the industry at the national level was substituted for the analogous establishment-level ratio.

${ }^{29}$ For the very small number of observations with positive cost of purchased electricity but no reported quantity of purchased electricity, the quantity of purchased electricity was estimated by dividing the reported cost of purchased electricity by the energy price for electricity sales to the industrial sector in the state contained in the State Energy

Data System.
} 
directly from the LRD. Labor costs are derived by totaling production worker wages and salaries, other worker wages and salaries, and voluntary and legally required supplemental labor expenditures. Energy costs sum the cost of fuels and the cost of purchased electricity. ${ }^{30}$ Materials cost is the same as the measure of materials quantity. Cost shares are obtained by dividing each factor cost by the sum of capital, labor, energy, and materials costs.

Agglomeration Economies. For the labor pooling variable, the top 15 occupations for each industry are identified with the national staffing pattern matrix of the Bureau of Labor Statistics, and the values for $O_{c}$ and $O_{T c}$ are from the 1990 and 2000 Census Equal Employment Opportunity tabulations.

For the two supply pooling variables, the purchasing amounts are tabulated from the Make and Use tables of the Benchmark Input-Output Accounts of the United States from the Bureau of Economic Analysis. $E_{c m}$ and $E_{c s}$ are tabulated from the Longitudinal Business Database (LBD).

For the knowledge spillover variables, the academic fields relevant to each industry are: chemicals, materials science, and chemical engineering (plastics and rubber); materials science, computer science, mechanical engineering, and electrical engineering (metalworking machinery); materials science, computer science, mechanical engineering, electrical engineering, and physics (measuring and controlling devices). These fields were identified from a Carnegie Mellon survey of industrial research and development managers analyzed in Cohen et al. (2002), along with the author's judgment. Annual university research expenditures by academic field are tabulated from the National Science Foundation's CASPAR database. Patent counts are obtained from the CASSIS patent bibliographic information system of the Information Products Division of the U.S. Patent and Trademark Office (USPTO). The set $K$ of patent technology classifications relevant to each industry is adapted from a relevancy match between patent technology classes and industries produced by the USPTO and an inter-industry technology flow matrix developed by Koo (2005a) to identify cross-industry knowledge spillovers. The $N_{g x}$ measure of relative importance is a citation frequency, also from Koo (2005a).

Control Variables. Regional unemployment rates, household income levels, and

\footnotetext{
${ }^{30}$ For the very few observations with positive quantity of purchased electricity but no reported cost of purchased electricity, the cost of purchased electricity was estimated by multiplying the reported quantity of purchased electricity by the energy price for electricity sales to the industrial sector in the state contained in the State Energy Data System.
} 
population density variables are constructed for LMAs by combining county-level estimates. Unemployment rates are from the Local Area Unemployment Statistics of the United States Bureau of Labor Statistics. Median household income levels are from the Small Area Income and Poverty Estimates of the United States Census Bureau. Population density is calculated from population estimates published by the United States Census Bureau.

Establishment-level data from the Longitudinal Business Database (LBD) are used to construct the regional industrial diversity and historic diversity measures. The LBD is another confidential Census dataset compiled from establishment-level records that extends beyond manufacturing to cover nearly all non-farm private establishments but does not include detailed information on inputs and outputs. Because the LBD is not available prior to 1977, the historic diversity measure for the 1992 sample is from 1977.

\section{Appendix C: Tests of Model Restrictions}

The translog functional form allows properties that are commonly assumed in the process of production function estimation to be tested within the modeling framework. These properties entail model simplifications that can increase estimation efficiency, but should be justified by empirical testing rather than imposed beforehand (Kim 1992).

The translog function is homothetic if, for each standard input $i, \sum_{j} \beta_{i j}=0$, where the notation is from equation (1) in the main text and $j$ also indexes the standard inputs. Homogeneity requires both homotheticity and, in addition, that $\sum_{k} \lambda_{i k}=0$ for each standard input $i$. The production function is linearly homogeneous if the conditions for homogeneity hold along with constant returns to scale: $\sum_{i} \alpha_{i}=0$. The translog function asymptotically incorporates the Cobb-Douglas and CES forms (Bairam 1998). ${ }^{31}$ The test for the Cobb-Douglas specification is whether $\beta_{i j}=0$ for each pair of standard inputs $i \neq j$. The translog approximates the CES specification in the neighborhood around $\rho=0$ if the terms $\frac{\beta_{i j}}{\alpha_{i} \alpha_{j}}$ are

\footnotetext{
${ }^{31}$ More precisely, the translog provides a local second-order approximation to the Cobb-Douglas and CES specifications.
} 
equal for each pair $i \neq j \cdot{ }^{32}$ The effect of the element $Z_{k}$ on productivity is Hicks-neutral, i.e. non-factor-augmenting, if $\lambda_{i k}=0$ for each standard input $i$.

Table C1 displays the test results. The three conditions of homotheticity, homogeneity, and constant returns to scale are rejected strongly in each model. The Cobb-Douglas specification is rejected strongly in each of the nine industry-year models. The CES formulation is rejected strongly in six of the nine models, and rejected weakly in one more. ${ }^{33}$ The CobbDouglas and CES specifications do not suffice to model the relationships indicated by the application of the translog form. For labor pooling and the two knowledge spillover variables, Hicks neutrality is rejected at the 90 percent confidence level in each model. The Hicks neutrality of regional industrial dominance is rejected in all but one case, measuring and controlling devices in 2002. There is more variety in the results for manufactured inputs and producer services across the different years and industries, but a majority of the models favor factor augmentation by the two supply pooling variables. The factor augmenting form is retained for each variable to maintain ready comparisons across all of the variables and samples.

\footnotetext{
${ }^{32}$ The CES test detailed here is based on an alternative specification of the translog production function and cost share system developed by Hoff (2002). There are six distinct $\frac{\beta_{i j}}{\alpha_{i} \alpha_{j}}$ terms, so the condition that each is equal to the same unspecified constant represents five restrictions.

${ }^{33}$ Because the CES test entails an alternative specification of the translog function in which the restricted parameter estimates fail to converge using the study samples, the Wald statistic is displayed in place of the likelihood ratio.
} 
Table C1. Tests of Model Restrictions.

\begin{tabular}{|c|c|c|c|c|c|c|c|c|c|}
\hline \multirow{3}{*}{$\begin{array}{l}\text { SIC } \\
\text { Industry } \\
\text { Year }\end{array}$} & \multicolumn{3}{|c|}{30} & \multicolumn{3}{|c|}{354} & \multicolumn{3}{|c|}{382} \\
\hline & \multicolumn{3}{|c|}{ rubber \& plastics } & \multicolumn{3}{|c|}{ metalworking machinery } & \multicolumn{3}{|c|}{ measuring \& controlling devices } \\
\hline & 1992 & 1997 & 2002 & 1992 & 1997 & 2002 & 1992 & 1997 & 2002 \\
\hline \multicolumn{10}{|l|}{ Hicks-Neutrality Tests } \\
\hline Dominance & $\begin{array}{r}44.52 \\
(0.000)\end{array}$ & $\begin{array}{r}13.25 \\
(0.010)\end{array}$ & $\begin{array}{r}14.50 \\
(0.006)\end{array}$ & $\begin{array}{r}31.40 \\
(0.000)\end{array}$ & $\begin{array}{r}43.39 \\
(0.000)\end{array}$ & $\begin{array}{r}26.15 \\
(0.000)\end{array}$ & $\begin{array}{r}21.70 \\
(0.000)\end{array}$ & $\begin{array}{r}15.30 \\
(0.004)\end{array}$ & $\begin{array}{r}4.53 \\
(0.339)\end{array}$ \\
\hline Labor Pooling & $\begin{array}{r}14.60 \\
(0.006)\end{array}$ & $\begin{array}{r}80.24 \\
(0.000)\end{array}$ & $\begin{array}{r}111.42 \\
(0.000)\end{array}$ & $\begin{array}{r}10.32 \\
(0.035)\end{array}$ & $\begin{array}{r}16.45 \\
(0.002)\end{array}$ & $\begin{array}{r}44.08 \\
(0.000)\end{array}$ & $\begin{array}{r}71.74 \\
(0.000)\end{array}$ & $\begin{array}{r}11.93 \\
(0.018)\end{array}$ & $\begin{array}{r}17.30 \\
(0.002)\end{array}$ \\
\hline Manufactured Inputs & $\begin{array}{r}19.40 \\
(0.001)\end{array}$ & $\begin{array}{r}7.37 \\
(0.118)\end{array}$ & $\begin{array}{r}1.97 \\
(0.741)\end{array}$ & $\begin{array}{r}27.97 \\
(0.000)\end{array}$ & $\begin{array}{r}2.77 \\
(0.597)\end{array}$ & $\begin{array}{r}7.80 \\
(0.099)\end{array}$ & $\begin{array}{r}39.84 \\
(0.000)\end{array}$ & $\begin{array}{r}3.40 \\
(0.494)\end{array}$ & $\begin{array}{r}17.59 \\
(0.001)\end{array}$ \\
\hline Producer Services & $\begin{array}{r}23.23 \\
(0.000)\end{array}$ & $\begin{array}{r}7.54 \\
(0.110)\end{array}$ & $\begin{array}{r}5.03 \\
(0.284)\end{array}$ & $\begin{array}{r}49.94 \\
(0.000)\end{array}$ & $\begin{array}{r}3.44 \\
(0.487)\end{array}$ & $\begin{array}{r}31.27 \\
(0.000)\end{array}$ & $\begin{array}{r}21.00 \\
(0.000)\end{array}$ & $\begin{array}{r}3.16 \\
(0.532)\end{array}$ & $\begin{array}{r}16.74 \\
(0.002)\end{array}$ \\
\hline Research & $\begin{array}{r}44.69 \\
(0.000)\end{array}$ & $\begin{array}{r}69.12 \\
(0.000)\end{array}$ & $\begin{array}{r}57.16 \\
(0.000)\end{array}$ & $\begin{array}{r}50.54 \\
(0.000)\end{array}$ & $\begin{array}{r}58.15 \\
(0.000)\end{array}$ & $\begin{array}{r}38.41 \\
(0.000)\end{array}$ & $\begin{array}{r}18.82 \\
(0.001)\end{array}$ & $\begin{array}{r}16.40 \\
(0.003)\end{array}$ & $\begin{array}{r}11.97 \\
(0.018)\end{array}$ \\
\hline Patents & $\begin{array}{r}24.89 \\
(0.000)\end{array}$ & $\begin{array}{r}43.61 \\
(0.000)\end{array}$ & $\begin{array}{r}41.49 \\
(0.000)\end{array}$ & $\begin{array}{r}8.94 \\
(0.063)\end{array}$ & $\begin{array}{r}18.47 \\
(0.001)\end{array}$ & $\begin{array}{r}8.57 \\
(0.073)\end{array}$ & $\begin{array}{r}9.41 \\
(0.052)\end{array}$ & $\begin{array}{r}8.31 \\
(0.081)\end{array}$ & $\begin{array}{r}13.43 \\
(0.009)\end{array}$ \\
\hline \multicolumn{10}{|l|}{ Technology Properties } \\
\hline Homotheticity & $\begin{array}{r}218.31 \\
(0.000)\end{array}$ & $\begin{array}{r}247.94 \\
(0.000)\end{array}$ & $\begin{array}{r}718.42 \\
(0.000)\end{array}$ & $\begin{array}{r}145.33 \\
(0.000)\end{array}$ & $\begin{array}{r}164.69 \\
(0.000)\end{array}$ & $\begin{array}{r}400.55 \\
(0.000)\end{array}$ & $\begin{array}{r}35.96 \\
(0.000)\end{array}$ & $\begin{array}{r}63.11 \\
(0.000)\end{array}$ & $\begin{array}{r}41.06 \\
(0.000)\end{array}$ \\
\hline Homogeneity & $\begin{array}{r}232.58 \\
(0.000)\end{array}$ & $\begin{array}{r}330.82 \\
(0.000)\end{array}$ & $\begin{array}{r}820.30 \\
(0.000)\end{array}$ & $\begin{array}{r}156.35 \\
(0.000)\end{array}$ & $\begin{array}{l}182.86 \\
(0.000)\end{array}$ & $\begin{array}{r}440.16 \\
(0.000)\end{array}$ & $\begin{array}{r}18,346 \\
(0.000)\end{array}$ & $\begin{array}{r}76.52 \\
(0.000)\end{array}$ & $\begin{array}{r}61.39 \\
(0.000)\end{array}$ \\
\hline Constant Returns to Scale & $\begin{array}{r}450.50 \\
(0.000)\end{array}$ & $\begin{array}{r}551.08 \\
(0.000)\end{array}$ & $\begin{array}{l}1,015.0 \\
(0.000)\end{array}$ & $\begin{array}{r}224.58 \\
(0.000)\end{array}$ & $\begin{array}{r}290.37 \\
(0.000)\end{array}$ & $\begin{array}{l}537.91 \\
(0.000)\end{array}$ & $\begin{array}{r}24,509 \\
(0.000)\end{array}$ & $\begin{array}{l}149.31 \\
(0.000)\end{array}$ & $\begin{array}{l}141.22 \\
(0.000)\end{array}$ \\
\hline \multicolumn{10}{|l|}{ Functional Simplifications } \\
\hline CES & $\begin{array}{r}75.55 \\
(0.0000)\end{array}$ & $\begin{array}{r}100.14 \\
(0.0000)\end{array}$ & $\begin{array}{r}53.32 \\
(0.0000)\end{array}$ & $\begin{array}{r}85.38 \\
(0.0000)\end{array}$ & $\begin{array}{r}77.44 \\
(0.0000)\end{array}$ & $\begin{array}{r}6.80 \\
(0.2356)\end{array}$ & $\begin{array}{r}6.28 \\
(0.2804)\end{array}$ & $\begin{array}{r}10.66 \\
(0.0586)\end{array}$ & $\begin{array}{r}14.20 \\
(0.0144)\end{array}$ \\
\hline Cobb-Douglas & $\begin{array}{r}79,106 \\
(0.0000)\end{array}$ & $\begin{array}{r}99,547 \\
(0.0000)\end{array}$ & $\begin{array}{r}72,025 \\
(0.0000)\end{array}$ & $\begin{array}{r}63,451 \\
(0.0000)\end{array}$ & $\begin{array}{r}74,871 \\
(0.0000)\end{array}$ & $\begin{array}{r}44,755 \\
(0.0000)\end{array}$ & $\begin{array}{r}12,125 \\
(0.0000)\end{array}$ & $\begin{array}{r}15,443 \\
(0.0000)\end{array}$ & $\begin{array}{r}8,537.3 \\
(0.0000)\end{array}$ \\
\hline
\end{tabular}

Note: All statistics derived from likelihood ratio tests except that the CES test uses the Wald statistic; figures in parentheses are probability values. 


\section{REFERENCES}

Acs, Z. J. 1996. Small Firms and Economic Growth. In P. H. Admiraal (ed.), Small Business in the Modern Economy: 1-62. Oxford, United Kingdom: Blackwell Publishers.

Acs, Z. J., L. Anselin, and A. Varga. 2002. Patents and innovation counts as measures of regional production of new knowledge. Research Policy, 31 (7): 1069-1085.

Acs, Z. J., and D. B. Audretsch. 1990. Innovation and Small Firms. Cambridge, Massachusetts: MIT Press.

Acs, Z. J., R. Morck, and B. Yeung. 1999. Productivity growth and firm size distribution. In Z. J. Acs, B. Carlsson, and C. Karlsson (eds.), Entrepreneurship, Small and Medium-Sized Enterprises and the Macroeconomy: 367-396. Cambridge, United Kingdom: Cambridge University Press.

Agrawal, A., and I. Cockburn. 2003. The anchor tenant hypothesis: exploring the role of large, local, R\&D-intensive firms in regional innovation systems. International Journal of Industrial Organization, 21: 1227-1253.

Aiken, L. S., and S. G. West. 1991. Multiple Regression: Testing and Interpreting Interactions. Newbury Park, California: Sage.

Amato, L. 1995. The choice of structure measure in industrial economics. Quarterly Journal of Business and Economics, 34 (2): 39-52.

Anselin, L. 2002. Under the hood: issues in the specification and interpretation of spatial regression models. Agricultural Economics, 27 (3): 247-267.

Armington, C., and Z. J. Acs. 2002. The determinants of regional variation in new firm formation. Regional Studies, 36 (1): 33-45.

Audretsch, D. B. 2001. Research issues relating to structure, competition, and performance of small technology-based firms. Small Business Economics, 16 (1): 37-51.

Audretsch, D. B. 2003. Innovation and spatial externalities. International Regional Science Review, 26 (2): 167-174.

Audretsch, D. B., L. Klomp, E. Santarelli, and R. Thurik. 2004. Gibrat's Law: are the services different? Review of Industrial Organization, 24 (3): 301-324.

Bairam, E. I. 1998. The popular and some new non-homogeneous production functions. In E. I. Bairam (ed.), Production and Cost Functions: Specification, Measurement, and Applications: 1-16. Aldershot, United Kingdom: Ashgate.

Beck, T., A. Demirguc-Kunt, and V. Maksimovic. 2005. Financial and legal constraints to growth: does firm size matter? The Journal of Finance, 60 (1): 137-177.

Berger, A. N., and G. F. Udell. 2002. Small business credit availability and relationship lending: the importance of bank organisational structure. The Economic Journal, 112 (477): F32-53.

Berndt, E. R. 1991. The Practice of Econometrics: Classic and Contemporary. Reading, Massachusetts: Addison-Wesley.

Blackorby, C., and R. R. Russell. 1989. Will the real elasticity of substitution please stand up? (A comparison of the Allen/Uzawa and Morishima elasticities.). The American Economic Review, 79 (4): 882-888.

Blair, J. P. 1978. Establishment size, market organization, and interindustry linkages. Growth and Change, 9 (4): 42-47.

Booth, D. E. 1986. Long waves and uneven regional growth. Southern Economic Journal, 53 (2): 448-460. 
Carlino, G. A. 1987. Comparisons of agglomeration: or what Chinitz really said: a reply. Urban Studies, 24 (1): 75-76.

Carree, M., and R. Thurik. 1999. Industrial structure and economic growth. In D. B. Audretsch, and R. Thurik (eds.), Innovation, Industry Evolution, and Employment: 86-110. Cambridge, United Kingdom: Cambridge University Press.

Caves, R. E. 1998. Industrial organization and new findings on the turnover and mobility of firms. Journal of Economic Literature, 36 (4): 1947-1982.

Caves, R. E., and D. R. Barton. 1990. Efficiency in U.S. manufacturing industries. Cambridge, Massachusetts: MIT Press.

Chambers, R. G. 1988. Applied Production Analysis: A Dual Approach. Cambridge, United Kingdom: Cambridge University Press.

Chinitz, B. 1961. Contrasts in agglomeration: New York and Pittsburgh. The American Economic Review, 51 (2): 279-289.

Chung, J. W. 1994. Utility and Production Functions: Theory and Applications. Oxford, United Kingdom: Blackwell.

Clark, G. L., M. S. Gertler, and J. E. M. Whiteman. 1986. Regional Dynamics: Studies in Adjustment Theory. Boston, Massachusetts: Allen and Unwin.

Cohen, W. M., R. R. Nelson, and J. P. Walsh. 2002. Links and impacts: the influence of public research on industrial R\&D. Management Science, 48 (1): 1-23.

Cole, R. A., L. G. Goldberg, and L. J. White. 2004. Cookie cutter vs. character: the micro structure of small business lending by large and small banks. Journal of Financial and Quantitative Analysis, 39 (2): 227-251.

Davies, S. W., and P. A. Geroski. 1997. Changes in concentration, turbulence, and the dynamics of market shares. The Review of Economics and Statistics, 79 (3): 383-391.

Doms, M. E. 1996. Estimating capital efficiency schedules within production functions. Economic Inquiry, 34 (1): 78-92.

Drennan, M. P., S. Larsen, J. Lobo, D. Strumsky, and W. Utomo. 2002. Sectoral shares, specialization and metropolitan wages in the United States, 1969-96. Urban Studies, 39 (7): 1129-1142.

Dumais, G., G. Ellison, and E. L. Glaeser. 1997. Geographic concentration as a dynamic process. Working Paper: National Bureau of Economic Research.

Dwyer, D. W. 1997. Productivity races II: the issue of capital measurement. Working Paper: Center for Economic Studies, United States Census Bureau. Available at http://www.ces.census.gov/index.php/ces/1.00/cespapers?down_key=100259 (accessed September 29, 2007).

Enright, M. J. 1995. Organization and coordination in geographically concentrated industries. In N. R. Lamoreau, and D. M. G. Raff (eds.), Coordination and Information: Historical Perspectives on the Organization of Enterprise: 103-146. Chicago, Illinois: University of Chicago Press.

Enright, M. J. 2000. The globalization of competition and the localization of competitive advantage: policies toward regional clustering. In N. Hood, and S. Young (eds.), The Globalization of Multinational Enterprise Activity and Economic Development: 303-331. London, United Kingdom: MacMillan.

Evans, A. W. 1986. Comparisons of agglomeration: or what Chinitz really said. Urban Studies, 23 (5): 387-389. 
Feldman, M. P., and D. B. Audretsch. 1999. Innovation in cities: science-based diversity, specialization, and localized competition. European Economic Review, 43 (2): 409-429.

Feser, E. J. 1998. Enterprises, external economies, and economic development. Journal of Planning Literature, 12 (3): 283-302.

Feser, E. J. 2001a. Agglomeration, enterprise size, and productivity. In B. Johansson, C. Karlsson, and R. Stough (eds.), Theories of Endogenous Regional Growth: Lessons for Regional Policies: 231-251. Berlin, Germany: Springer-Verlag.

Feser, E. J. 2001b. A flexible test for agglomeration economies in two US manufacturing industries. Regional Science and Urban Economics, 31 (1): 1-19.

Feser, E. J. 2002. Tracing the sources of local external economies. Urban Studies, 39 (13): 2485-2506.

Fogarty, M. S., and G. A. Garofalo. 1988. Urban spatial structure and productivity growth in the manufacturing sector of cities. Journal of Urban Economics, 23 (1): 60-70.

Fritsch, M., and R. Lukas. 1999. Innovation, cooperation, and the region. In D. B. Audretsch, and R. Thurik (eds.), Innovation, Industry Evolution, and Employment: 157-181. Cambridge, United Kingdom: Cambridge University Press.

Fritsch, M., and M. Meschede. 2001. Product innovation, process innovation, and size. Review of Industrial Organization, 19 (3): 335-350.

Frondel, M., and C. M. Schmidt. 2002. The capital-energy controversy: an artifact of cost shares? The Energy Journal, 23 (3): 53-79.

Gerking, S. 1994. Measuring productivity growth in U.S. regions: a survey. International Regional Science Review, 16 (1-2): 155-185.

Gilbert, B. A., P. P. McDougall, and D. B. Audretsch. 2006. New venture growth: a review and extension. Journal of Management, 32 (6): 926-950.

Glaeser, E. L., H. D. Kallal, J. A. Scheinkman, and A. Schleifer. 1992. Growth in cities. Journal of Political Economy, 100 (6): 1126-1152.

Golan, A., G. Judge, and J. M. Perloff. 1996. Estimating the size distribution of firms using government summary statistics. The Journal of Industrial Economics, 44 (1): 69-80.

Gopinath, M., D. Pick, and Y. Li. 2004. An empirical analysis of productivity growth and industrial concentration in US manufacturing. Applied Economics, 36 (1): 1-17.

Gordon, I. R., and P. McCann. 2000. Industrial clusters: complexes, agglomeration, and/or social networks? Urban Studies, 37 (3): 513-532.

Gort, M., and N. Sung. 1999. Competition and productivity growth: the case of the U.S. telephone industry. Economic Inquiry, 37 (4): 678-691.

Greene, W. H. 2003. Econometric Analysis. 5th Ed. Upper Saddle River, New Jersey: Prentice Hall.

Hay, D. A., and D. J. Morris. 1991. Industrial Economics and Organization: Theory and Evidence. Oxford, United Kingdom: Oxford University Press.

Helmsing, A. H. J. B. 2001. Externalities, learning and governance: new perspectives on local economic development. Development and Change, 32: 277-308.

Helper, S. 1991. Strategy and irreversibility in supplier relations: the case of the U.S. automobile industry. Business History Review, 65 (4): 781-823.

Henderson, J. V. 2003. Marshall's scale economies. Journal of Urban Economics, 53 (1): 128.

Henderson, J. V., A. Kuncoro, and M. A. Turner. 1995. Industrial development in cities. Journal of Political Economy, 103 (5): 1067-1090. 
Henderson, J. V., Z. Shalizi, and A. J. Venables. 2001. Geography and development. Journal of Economic Geography, 1 (1): 81-105.

Henderson, R., A. B. Jaffe, and M. Trajtenberg. 1998. Universities as a source of commercial technology: a detailed analysis of university patenting, 1965-1988. The Review of Economics and Statistics, 80 (1): 119-127.

Hoff, A. 2002. The translog approximation of the constant elasticity of substitution production function with more than two input variables. Working Paper: Danish Research Institute of Food Economics, Fisheries Economics and Management Division. Available at http://www.foi.kvl.dk/upload/foi/docs/publikationer/working\%20papers/2002/14.pdf (accessed September 29, 2007).

Hoogstra, G. J., and J. van Dijk. 2004. Explaining firm employment growth: does location matter? Small Business Economics, 22 (3-4): 179-192.

Hoover, E. M. 1937. Location Theory and the Shoe Leather Industries. Cambridge, Massachusetts: Harvard University Press.

$\mathrm{Hu}, \mathrm{P}$., and J. Pooler. 2002. An empirical test of the competing destinations model. Journal of Geographical Systems, 4 (3): 301-323.

Hu, T.-s., C.-y. Lin, and S.-L. Chang. 2005. Role of interaction between technological communities and industrial clustering in innovative activity: the case of Hsinchu District, Taiwan. Urban Studies, 42 (7): 1139-1160.

Ijiri, Y., and H. A. Simon. 1977. Skew Distributions and the Sizes of Business Firms. Amsterdam, Netherlands: North-Holland Publishing.

Jacobs, J. 1969. The Economy of Cities. New York, New York: Random House.

Jaffe, A. B. 1989. Real effects of academic research. The American Economic Review, 79 (5): 957-970.

Jaffe, A. B., M. Trajtenberg, and R. Henderson. 1993. Geographic localization of knowledge spillovers as evidenced by patent citations. The Quarterly Journal of Economics, 108 (3): 577-598.

Kim, H. Y. 1992. The translog production function and variable returns to scale. The Review of Economics and Statistics, 74: 546-551.

Kirchhoff, B. A., C. Armington, I. Hasan, and S. L. Newbert. 2002. The Influence of R\&D Expenditures on New Firm Formation and Economic Growth. Washington, D.C.: National Commission on Entrepreneurship.

Klagge, B., and R. Martin. 2005. Decentralised versus centralised financial systems: is there a case for local capital markets? Journal of Economic Geography, 5 (4): 387-421.

Koo, J. 2002. Agglomeration and spillovers in a simultaneous framework. Doctoral Dissertation, Department of City and Regional Planning, University of North Carolina: Chapel Hill, North Carolina.

Koo, J. 2005a. Knowledge-based industry clusters: evidenced by geographical patterns of patents in manufacturing. Urban Studies, 42 (9): 1487-1505.

Koo, J. 2005b. Agglomeration and spillovers in a simultaneous framework. Annals of Regional Science, 39 (1): 35-47.

Malecki, E. J. 1994. Entrepreneurship in regional and local development. International Regional Science Review, 16 (1-2): 119-153.

Malmberg, A. 1996. Industrial geography: agglomeration and local milieu. Progress in Human Geography, 20 (3): 392-403. 
Malmberg, A., B. Malmberg, and P. Lundequist. 2000. Agglomeration and firm performance: economies of scale, localisation, and urbanisation among Swedish export firms. Environment and Planning A, 32 (2): 305-321.

Malmberg, A., and P. Maskell. 2002. The elusive concept of localization economies: towards a knowledge-based theory of spatial clustering. Environment and Planning A, 34 (3): 429449.

Marshall, A. [1890] 1910. Principles of Economics. 6th Ed. London, United Kingdom: MacMillan.

Martin, S. A., R. McHugh, and S. R. Johnson. 1991. The influence of location on productivity: manufacturing technology in rural and urban areas. Working Paper: Center for Economic Studies, United States Census Bureau. Available at http://www.ces.census.gov/index.php/ces/1.00/cespapers?down_key=100148 (accessed September 29, 2007).

Mason, C. M. 1991. Spatial variations in enterprise: the geography of new firm formation. In R. Burrows (ed.), Deciphering the Enterprise Culture: Entrepreneurship, Petty Capitalism, and the Restructuring of Britain: 74-107. London, United Kingdom: Routledge.

Matkin, G. W. 1990. Technology Transfer and the University. New York: MacMillan.

Moomaw, R. L. 1983. Spatial productivity variations in manufacturing: a critical survey of cross-sectional analyses. International Regional Science Review, 8 (1): 1-22.

Moomaw, R. L. 1988. Agglomeration economies: localization or urbanization? Urban Studies, 25 (2): 150-161.

Moretti, E. 2004. Workers' education, spillovers, and productivity: evidence from plant-level production functions. The American Economic Review, 94 (3): 656-690.

Mukkala, K. 2004. Agglomeration economies in the Finnish manufacturing sector. Applied Economics, 36 (21): 2419-2427.

Nelson, R. R., and S. G. Winter. 1982. An Evolutionary Theory of Economic Change. Cambridge, Massachusetts: Harvard University Press.

Nguyen, S. V., and A. P. Reznek. 1990. Returns to scale in small and large U.S. manufacturing establishments. Working Paper: Center for Economic Studies, United States Census Bureau. Available at http://www.ces.census.gov/index.php/ces/1.00/cespapers?down_key=100133 (accessed September 29, 2007).

Nickell, S. J. 1996. Competition and corporate performance. Journal of Political Economy, 104 (4): 724-746.

Nickell, S. J., D. Nicolitsas, and N. Dryden. 1997. What makes firms perform well? European Economic Review, 41 (3-5): 783-796.

Norton, R. D. 1992. Agglomeration and competitiveness: from Marshall to Chinitz. Urban Studies, 29 (2): 155-170.

Porter, M. E. 1990. The Competitive Advantage of Nations. New York: MacMillan.

Porter, M. E. 1998. Clusters and the new economics of competition. Harvard Business Review: 77-90.

Porter, M. E. 2000. Location, competition, and economic development: local clusters in a global economy. Economic Development Quarterly, 14 (1): 15-34. 
Porter, M. E. 2002. Clusters of Innovation: Regional Foundations of U.S. Competitiveness. Washington, D. C.: Council on Competitiveness. Prepared for Council on Competitiveness, Washington, D. C.

Powell, T. C. 2003. Varieties of competitive parity. Strategic Management Journal, 24 (1): 61-86.

Powell, T. C., and C. J. Lloyd. 2005. Toward a general theory of competitive dominance: comments and extensions on Powell (2003). Strategic Management Journal, 26 (4): 385-394.

Quigley, J. M. 1998. Urban diversity and economic growth. Journal of Economic Perspectives, 12 (2): $127-138$.

Renski, H. C. 2006. An investigation of the industrial ecology of business start-up survival. Doctoral Dissertation, Department of City and Regional Planning, University of North Carolina: Chapel Hill, North Carolina.

Renski, H. C., and E. J. Feser. 2004. Measuring the sources of agglomeration economies: a comparison of urbanization and localization indicators. Presented at 51st Annual North American Meetings of the Regional Science Council: Seattle, Washington, November 11-13.

Richardson, H. W. 1974. Agglomeration potential: a generalization of the income potential concept. Journal of Regional Science, 14 (3): 325-336.

Rigby, D. L., and J. Essletzbichler. 2002. Agglomeration economies and productivity differences in US cities. Journal of Economic Geography, 2 (4): 407-432.

Rosenfeld, S. A. 1996. Does cooperation enhance competitiveness? Assessing the impacts of inter-firm collaboration. Research Policy, 25 (2): 247-263.

Rosenthal, S. S., and W. S. Strange. 2003. Geography, industrial organization, and agglomeration. The Review of Economics and Statistics, 85 (2): 377-393.

Rosenthal, S. S., and W. S. Strange. 2004. Evidence on the Nature and Sources of Agglomeration Economies. In J. V. Henderson, and J.-F. Thisse (eds.), Handbook of Urban and Regional Economics, Vol. 4: 2119-2171. Amsterdam, Netherlands: Elsevier.

Sampat, B. N., D. C. Mowery, and A. A. Ziedonis. 2003. Changes in university patent quality after the Bayh-Dole act: a re-examination. International Journal of Industrial Organization, 21: 1371-1390.

Saxenian, A. 1994. Regional Advantage: Culture and Competition in Silicon Valley and Route 128. Cambridge, Massachusetts: Harvard University Press.

Scherer, F. M. 1980. Industrial Market Structure and Economic Performance. Second Ed. Boston, Massachusetts: Houghton Mifflin.

Schmalensee, R. 1989. Inter-industry studies of structure and performance. In R. Schmalensee, and R. D. Willig (eds.), Handbook of Industrial Organization: 951-1009. Amsterdam, Netherlands: Elsevier.

Scott, A. J. 1986. Industrial organization and location: division of labor, the firm, and spatial process. Economic Geography, 62 (3): 215-231.

Scott, A. J. 1988a. Metropolis: From the Division of Labor to Urban Form. Berkeley, California: University of California Press.

Scott, A. J. 1988b. New Industrial Spaces: Flexible Production Organization and Regional Development in North America and Western Europe. London, United Kingdom: Pion Limited. 
Scott, A. J., and E. C. Kwok. 1989. Inter-firm subcontracting and locational agglomeration: a case study of the printed circuits industry in Southern California. Regional Studies, 23 (5): 405-416.

Sorenson, O., and P. G. Audia. 2000. The social structure of entrepreneurial activity: geographical concentration of footwear production in the United States, 1940-1989. The American Journal of Sociology, 106 (2): 424-461.

Stigler, G. J. 1951. The division of labor is limited by the extent of the market. Journal of Political Economy, 59 (3): 185-193.

Sutton, J. 1997. Gibrat's legacy. Journal of Economic Literature, 35 (1): 40-59.

Syverson, C., J. C. Haltiwanger, and L. Foster. 2005. Reallocation, firm turnover, and efficiency: selection on productivity or profitability? Working Paper Available at http://www.ces.census.gov/index.php/ces/1.00/cespapers?down_key=101721 (accessed September 29, 2007).

Tornatzky, L. G., and M. Fleischer. 1990. The Processes of Technological Innovation. Lexington, Massachusetts: Lexington Books.

United States Department of Agriculture. 2003. Measuring Rurality: Commuting Zones and Labor Market Areas. Available at http://www.ers.usda.gov/briefing/rurality/lmacz (accessed September 29, 2007).

Usai, S., and M. Vannini. 2005. Banking structure and regional economic growth: lessons from Italy. Annals of Regional Science, 39 (4): 691-714.

Wagner, J. 2004. Are young and small firms hothouses for nascent entrepreneurs? Evidence from German micro data. Applied Economics Quarterly, 50 (4): 379-391.

Young, A. A. 1928. Increasing returns and economic progress. The Economic Journal, 38 (152): $527-542$. 